\title{
EL ART. 100.2 RP COMO EXPRESIÓN DEL SISTEMA DE INDIVIDUALIZACIÓN CIENTÍFICA Y DEL PRINCIPIO DE FLEXIBILIDAD: ALGUNOS DATOS SOBRE SU APLICACIÓN
}

\author{
Mª José Rodríguez Puerta* \\ "Uno de estos grandes descubrimientos del mundo moral es que el delincuente \\ sea susceptible de enmienda; que la sociedad debe procurársela, y que, siendo \\ el deber absoluto, la justicia obliga, aun para con los que faltan a ella." \\ CONCEPCIÓN ARENAL, Estudios penitenciarios, \\ Madrid, Imprenta de T. Fortanet, 1877. p.2.
}

Resumen: En el presente trabajo se analizarán las condiciones que justifican la obtención del régimen flexible previsto en el art. 100.2 Reglamento Penitenciario. Para ello se examinan los requisitos que

\section{Recibido: febrero 2021. Aceptado: julio 2021}

* Profesora Titular de Derecho Penal. ORCID: 0000-0001-9190-2701.

Facultad de Derecho de la Universidad Autónoma de Barcelona (UAB). Dirección Edifici B2, Bellaterra, Carrer de la Vall Moronta, S/N, 08193, Barcelona. Email: mariajose.rodriguez.puerta@uab.es

Google Académico: https://scholar.google.es/citations?hl=en\&user=r3 N1LA0AAAAJ 
impone la normativa penitenciaria y la aplicación que de esta medida está haciendo la Administración penitenciaria, tanto a nivel nacional como en Cataluña. Se pretende así probar la utilidad de este régimen para la individualización del tratamiento y, en especial, como instrumento flexibilizador de las condiciones de vida que se aplican a los internos que cumplen su pena clasificados en segundo grado, bajo el modelo de vida propio del régimen ordinario.

Palabras clave: Sistema de individualización científica, principio de flexibilidad, condiciones legales para la aplicación del art. 100.2 del Reglamento penitenciario, estadísticas.

\section{ARTICLE 100.2 RP AS AN EXPRESSION OF THE SCIENTIFIC PERSONALIZATION AND THE PRINCIPLE OF FLEXIBILITY: SOME DATA CONCERNING ITS IMPLEMENTATION}

Summary: This paper examines the conditions which justify the granting of the flexible prison regime provided for in Article 100.2 of the Spanish Prison Regulations. To this end, both the statutory requirements and the implementation of this precept by the prison administration at both the national and Catalan level will be analysed. The aim is to determine the usefulness of this flexible prison regime as a way to improve the personalization of rehabilitation programs; particularly, in order to make ordinary regime living conditions under which second-degree inmates serve their sentences more flexible.

Key Works: Personalization of prison rehabilitation programs, principle of flexibility, statutory requirements for the application of Art. 100.2 of the Spanish Prison Regulations, statistics. 


\section{Planteamiento}

En el presente trabajo se analizarán las condiciones que justifican la obtención del régimen flexible previsto en el art. 100.2 del Reglamento Penitenciario (en adelante RP) aplicable a los penados que requieren de algunas modificaciones regimentales para adaptar su vida en prisión a necesidades específicas del tratamiento. Para ello se estudiarán los requisitos que impone la normativa penitenciaria y la aplicación que de esta medida está haciendo la Administración penitenciaria, como primera indagación para poder reflexionar sobre su utilidad en el sistema penitenciario español.

Como se examinará más adelante, el porcentaje de penados que cumple su condena en este régimen flexible es elevado y son muchas y muy frecuentes las resoluciones que acuerdan su aplicación. Hasta hace no mucho tiempo la discusión sobre el principio de flexibilidad en la clasificación penitenciaria se había mantenido en el ámbito estrictamente académico/profesional y, pese a las posiciones encontradas a las que luego me referiré, no había trascendido a la opinión pública. Sin embargo, acontecimientos relativamente recientes han trasladado una parte del debate a los medios de comunicación. Esto se ha producido básicamente en relación con dos tipos de asuntos: la clasificación de algunos condenados por delitos económicos y/o de corrupción y últimamente también la de los condenados por el "proceso" en Cataluña. Efectivamente, conocemos por la prensa el historial penitenciario (clasificación, modificaciones de grado o permisos) de algunos de ellos. Casos como el de Pantoja ${ }^{1}$,

1 Isabel Pantoja fue condenada a dos años de prisión por la comisión de un delito de blanqueo, no se suspendió la pena, ni a ella ni a ninguno de los responsables en ese caso. Ingresó en el Centro Penitenciario de Alcalá de Guadaira (Sevilla) el 21 de noviembre de 2014. La Administración penitenciaria la clasificó en segundo grado y el JVP resolvió el recurso interpuesto por la interna, confirmando la clasificación y negando la posibilidad de aplicar el art. 100.2 RP. Transcurrido algo más de un año 
Pujol $^{2}$, Urdangarin ${ }^{3}$, Matas, Junqueras, Forcadell ${ }^{4}$ o incluso el de Rato ${ }^{5}$ ocupan portadas. En todos esos asuntos se ha sugerido la posibilidad de cumplir la condena conforme a lo dispuesto en el art. 100.2 RP.

La visibilidad mediática de estos casos parece haber despertado sospechas sobre la aplicación de esta previsión reglamentaria. Algunas informaciones sugieren la posibilidad de que se esté utilizando para hacer efectivos determinados privilegios y conseguir así una ejecución de la pena de prisión más indulgente ${ }^{6}$. Sin embargo, como trataré de demostrar, este régimen de vida cumple un papel destacado en la tarea de individualización del tratamiento y, en especial, como instrumento flexibilizador de las condiciones de vida que se aplican a los internos que cumplen su pena clasificados en segundo grado, bajo el modelo de vida propio del régimen ordinario.

(más de la mitad de la pena) fue clasificada en tercer grado y accedió al régimen de semilibertad.

2 Sobre las vicisitudes por las que ha discurrido el cumplimiento de la pena impuesta a Oriol Pujol, vid. ampliamente las noticias que recoge El País https://elpais.com/noticias/oriol-pujol-ferrusola/

3 La prensa se ha referido en múltiples ocasiones a su situación penitenciaria. Vid., por ejemplo, el recopilatorio informativo de El País en el que se contienen más de 12 noticias sobre las variaciones por las que ha atravesado el cumplimiento de la pena que se le impuso por los hechos enjuiciados en el caso "Nóos": https://elpais.com/noticias/operacionbabel/

4 El aluvión de noticias sobre los condenados por el "proceso" y la forma en la que cumplen las penas impuestas es abrumador. Vid. Algunas de las informaciones en la prensa sobre la situación penitenciaria de algunos de ellos: https://elpais.com/noticias/sentencia-juicio-proces/

5 Sobre el modo en que cumple la pena de prisión, vid. la información sobre la concesión del tercer grado con control telemático: https://elpais. com/economia/2020-10-01/la-audiencia-nacional-excarcela-rato-bajocontrol-telematico.html

6 Sobre la necesidad de examinar conforme a parámetros distintos los factores relacionados con la actividad delictiva en el caso de los delincuentes económicos, para valorar la forma en que éstos deben cumplir las penas de prisión impuestas, Vid. JUANATEY DORADO, C. (2017), 


\section{El principio de flexibilidad en la normativa penitenciaria}

Con la aprobación de la Ley Orgánica General Penitenciaria (en adelante LOGP) se consagró, a ojos de un importante sector de la doctrina, el paso de un sistema progresivo clásico, caracterizado por la rigidez y la dependencia de variables objetivas -como la duración de la condena impuesta-, a uno flexible y articulado en torno a las necesidades individuales (subjetivas) del tratamiento del penado, esto es, un sistema de individualización científica (art. 72 LOGP) ${ }^{7}$. Se

"Función y fines de la pena: la ejecución de penas privativas de libertad en el caso de los delincuentes de cuello blanco", en Revista Penal, n ${ }^{\circ} 40-$ Julio 2017, pp.135 y ss.

En todo caso, la validez de los criterios y de las diversas instituciones penitenciarias dirigidas a facilitar el cumplimiento de la pena en entornos de mayor liberad, no pueden verse comprometidas por la irrupción en el ámbito penitenciario de esta forma de delincuencia. Tampoco considero que un mayor tiempo en prisión o un cumplimiento sometido a mayores restricciones de libertad sea la vía correcta para actuar sobre esta clase de delincuentes ni para prevenir la delincuencia de cuello blanco.

7 Vid. sobre las características de este nuevo modelo LEGANES GÓMEZ, S. (2005), La evolución de la clasificación penitenciaria, Premio Nacional Vitoria Kent 2004, Madrid: Ed. Ministerio del Interior. Secretaría General Técnica, p.64 y también FERNÁNDEZ BERMEJO, D. (2013), Individualización científica y tratamiento en prisión, en Premio Vitoria Kent, Madrid: Ministerio del Interior-Secretaria Técnica, p. 480. Más recientemente sobre esta cuestión CERVELLÓ DONDERÍS, V. (2016), Derecho penitenciario, $4^{\text {a }}$ Ed., Valencia: Tirant Lo Blanch, p.221 y MIR PUIG, C. (2015), Derecho penitenciario. El cumplimiento de la pena privativa de libertad, $3^{\mathrm{a}}$ Ed., Barcelona: Atelier, p.97.

El RP confirma además la posibilidad de clasificar en tercer grado inicial a cualquier interno sin necesidad de haber cumplido una parte determinada de la pena. El art. 104.3 RP, en el marco de lo que denomina "casos especiales", establece que podrá acordarse la clasificación (inicial o progresión) en tercer grado aún sin haber cumplido la cuarta parte de la condena. Reconoce así que se trata de una situación especial pero posible. En esos supuestos únicamente se requiere que haya "transcurrido el tiempo de estudio suficiente para obtener un adecuado conocimiento del interno" Vid. en este sentido, entre otras, CERVELLÓ DONDERÍS, V. (2005), "La clasificación en tercer grado como instrumento de resocialización", en El juez de vigilancia y el tratamiento penitenciarios, en Estudios de Derecho Judicial, p. 84. Sobre la interpretación de ese 
transitó así de un modelo de ejecución de la pena en el que se requería de un mínimo de cumplimiento para progresar en grado, a otro modelo en el que se podía situar al interno en cualquier grado dependiendo exclusivamente de sus circunstancias personales y de las necesidades del tratamiento ${ }^{8}$. Aunque ya no era imprescindible transitar por todos los grados para terminar cumpliendo en régimen de semilibertad, tanto la LOGP como posteriormente el RP, siguieron asignando un régimen de vida determinado para cada grado sin que pueda escogerse, de manera "particularizada", las condiciones de vida (el estatuto jurídico-penitenciario) más adecuadas para cada interno. A cada uno de los grados, primero, segundo y tercero, se le asigna un régimen, cerrado, ordinario y abierto, sin posibilidad de adaptarlos a las circunstancias que presenta el condenado.

En efecto, el art. 72.2 LOGP establece una clara correlación entre el grado de clasificación y el régimen de vida, que viene determinado legal y reglamentariamente. Pese a ello, para evitar la rigidez que provoca este sistema, el RP incluye determinadas previsiones que permiten dotar de mayor "flexibilidad" al sistema de clasificación en grados. Esto es, la norma reglamentaria introduce mecanismos que posibilitan

requisito vid. AAP de Barcelona 5938/2019 de 10/07/2019 (caso ORIOL PUJOL) en el que se confirma, en vía de recurso, la clasificación inicial del penado en tercer grado tras casi dos meses de observación. En ese caso, la propuesta de clasificación se adoptó por unanimidad después de comprobar la concurrencia de un buen número de variables positivas.

Recientemente la Administración penitenciaria ha aprobado la Instrucción 6/2020 de 17 de diciembre en la que se establece el protocolo de ingreso directo en medio abierto, y las condiciones que deberán cumplirse para llevar a cabo una clasificación inicial en tercer grado, que coinciden básicamente con las examinadas en esa resolución. También la Administración catalana ha aprobado, en noviembre de 2020, un protocolo de ingreso y clasificación en centros penitenciarios abiertos.

8 Vid. ampliamente sobre los modelos penitenciarios y el tránsito de la legislación penitenciaria de uno a otro FERNANDEZ ARÉVALO, L /NISTAL BURÓN, J (2012), Manual de derecho penitenciario, $2^{\mathrm{a}} \mathrm{Ed}$, Pamplona: Thomson-Aranzadi, p. 263 y ss. 
la adaptación de las condiciones de vida de los grados a las necesidades individuales de los internos clasificados. De entre estas previsiones destacaría tres. En primer lugar, la existencia de sub-regímenes que permiten diversificar las condiciones de vida dentro de un mismo grado. En segundo lugar, la posibilidad de acordar salidas al exterior para cumplir un programa de atención especializada a determinados internos clasificados en segundo grado (art. $117 R P$ ). Y, por último, el régimen flexible o mixto, previsto en el art. 100.2 RP, objeto principal de este indagación. Veamos en qué consisten estas tres manifestaciones del principio de flexibilidad.

\subsection{Los diversos regímenes de vida dentro de cada grado: una primera manifestación de la necesaria flexibili- dad en la asignación de regímenes de vida para adecuarlos a las necesidades del tratamiento}

Tal y como se ha señalado, el RP procede a precisar sub-regímenes de vida. Esta diversificación dentro de un mismo régimen permite que internos clasificados en un mismo grado puedan llevar vidas distintas, más acorde con sus características y sus necesidades tratamentales.

En esta dirección, el RP distingue dos modalidades de vida en régimen cerrado (art. $91 \mathrm{RP}$ ). Así, prevé en primer lugar una forma de ejecución en primer grado más estricta, cuyo cumplimiento se lleva a cabo en Departamentos especiales. Esta forma de vida se aplica a penados que han sido protagonistas o inductores de alteraciones regimentales muy graves, que han puesto en peligro la vida o integridad de los funcionarios, autoridades, otros internos o personas ajenas a la Institución (art. $93 \mathrm{RP}$ ). Junto a esta, dispone una segunda modalidad de cumplimiento, un sub-régimen cerrado "común". Esta forma de cumplimiento resulta aplicable a los clasificados en primer grado que muestran una manifiesta inadaptación al régimen ordinario, pero que no presentan una peligrosidad extrema (art. 94 RP). En estos últimos casos la pena se cumple en centros o departamentos cerrados. 
También el propio RP lleva a cabo una subdivisión del régimen abierto. En los art. 82 y $84 \mathrm{RP}$ se disponen distintas modalidades de ejecución en tercer grado cuya asignación se hace depender de factores individuales y de las propias necesidades de tratamiento. Estas formas de vida, que van de menos a más libertad, son las siguientes: régimen abierto restringido, régimen abierto común y régimen abierto de cumplimiento en la comunidad (Unidades dependientes, Unidades extra penitenciarias y régimen abierto del art. 86.4 CP).

El primero de los sub-regímenes, el régimen abierto restringido (art. $82 \mathrm{RP}$ ), integra la forma de cumplimiento más estricta del tercer grado. Se trata de una forma de vida a caballo entre el régimen ordinario y el abierto prevista para condenados clasificados en tercer grado que han alcanzado, como indica CERVELLÓ, una incipiente capacidad de vida en libertad, pero que requiere todavía reforzarla ${ }^{9}$. Este régimen de vida permite limitar el contacto del interno con el exterior y suele acordarse para penados con una peculiar trayectoria delictiva, personalidad anómala o condiciones personales diversas, como la ausencia de un trabajo en el exterior, la falta de medios de subsistencia o cuando el domicilio del condenado se encuentra alejado. En esos casos, las salidas al exterior se limitan, pudiendo el interno permanecer fuera del Centro para buscar trabajo, realizar tareas en centros de acogida o también para llevar a cabo salidas de fin de semana para acudir a su domicilio. En todo caso, lo esencial es que el penado amplía su contacto con el exterior respecto al que tenía en régimen ordinario (segundo grado) pero no alcanza cuotas de libertad elevadas ${ }^{10}$.

9 Vid. CERVELLÓ, V. (2005:178).

10 También se suele recurrir a este régimen restringido en aquellos casos en los que el penado es clasificado inicialmente en tercer grado. Vid., por ejemplo, AAP de Barcelona 6930/2020 de 26/06/2020 o AAP de Barcelona d 5341/2020 de 30/02/2020, por citar algunas resoluciones recientes. 
Junto a esta forma de ejecución, el RP prevé una modalidad común de cumplimiento del régimen abierto. Esta forma de vida se caracteriza por permitir salidas al exterior para desarrollar actividades laborales, formativas, familiares, de tratamiento o de otro tipo, que faciliten la integración social. Estas salidas deben ser planificadas y reguladas por la Junta de Tratamiento que es quien decide los horarios y actividades propias de este sub-régimen. En todo caso, el mínimo de permanencia en el Centro penitenciario es de ocho horas diarias, debiendo pernoctarse en el Establecimiento (art. 86.1, 2 y 3 RP). Las salidas, controles y demás obligaciones de los internos que cumplen de este modo el tercer grado son determinados por la Junta de Tratamiento (JT en adelante). Los internos que cumplen conforme a este régimen pueden disfrutar de permisos de fin de semana y salidas ordinarias (art. $154 \mathrm{RP}$ ). Por último, señalar que este régimen abierto común suele cumplirse en el propio Centro penitenciario, en secciones abiertas. Si bien, es posible también que se cumpla fuera del Centro penitenciario en Unidades Dependientes ${ }^{11}$ o según el modelo de cumplimiento dispuesto en el art. 86.4 RP. En estos últimos casos, los internos cumplen la pena fuera del Establecimiento penitenciario, lo que favorece una inserción más adecuada en la comunidad ${ }^{12}$. En el primero de

11 Cuando el interno clasificado en tercer grado requiere de tratamiento de deshabituación, el Centro Directivo puede autorizar su cumplimiento en una Unidad Extrapenitenciaria (art. 182 RP).

12 Sobre la incidencia en la tasa de reincidencia del grado en el que se finaliza la condena Vid. IBÀÑEZ, A. y CID J. (2016), "La reinserción de las personas que finalizan condena en régimen ordinario", publicado por el Centre d'Estudis Jurídics i Formació Especialitzada de Catalunya, p. 16. Se ha publicado recientemente un estudio en el que se indica que el "retorno progresivo a la sociedad durante la condena da mejores resultados para mantener a los internos desistentes en el delito". Constata el estudio, a partir del análisis de datos penitenciarios catalanes, que los que cumplen en tercer grado y, en particular fuera del Centro penitenciario (en Unidades Dependientes y conforme al régimen del art. 86.4 RP), se mantienen desistentes del delito en mayor porcentaje que los que finalizan su condena en segundo grado. Vid. CAPDEVILA CAPDEVILA, M. 
los supuestos, cumplen la pena en centros específicos habilitados para ello (arts. 165 y ss. RP), ubicados arquitectónicamente fuera de los Centros penitenciarios ${ }^{13}$. En el segundo, la cumplen en su domicilio, sometidos a medidas de control telemáticas o de otro tipo. En los casos del art. 86.4 RP, el interno al que se aplica este su-régimen únicamente deberá acudir al Centro Penitenciario para realizar actividades, como entrevistas o controles periódicos. Estas dos formas de cumplimiento son las que mayor libertad otorgan a los clasificados en tercer grado y se acercan ya al cumplimiento en régimen de libertad (libertad condicional), puesto que la pena se cumple íntegramente fuera de la prisión, en la comunidad $^{14}$.

En mi opinión, la previsión de distintos sub-regímenes permite adaptar mejor a las necesidades de tratamiento el cumplimiento de la pena de los internos clasificados en primer y tercer grado. Sin duda, al ofrecerse a la Administración penitenciaria un número más elevado de modelos de vida, se facilita la selección de aquel que resulta más acorde con las necesidades de tratamiento de los internos clasificados en esos dos grados. Además, y ello se constata particularmente en el régimen abierto, el escalonamiento de los modos de vida, desde el más restrictivo hasta el más cercano a la libertad, permite valorar la evolución del penado y asignarle consecuencias positivas. Esto es, la progresiva asunción de mayores cuotas de libertad.

(coord.) et al. (2019), "Tasa de reincidencia en la libertad condicional y de inactividad delictiva en 3er grado en Cataluña", publicado por el Centre d'Estudis Jurídics i Formació Especialitzada de Catalunya, p. 184 y 186.

13 En Unidades Dependientes o en Centros de Inserción Social. Sobre las distintas clases de centros y las diferencias entre ellos Vid., por todos, CERVELLÓ, V. (2015, 81 y ss.).

14 Vid. ampliamente sobre esta forma de cumplimiento la Instrucción 13/2006 sobre aplicación del art. 86.4 RP. 
La situación es distinta en relación con el régimen ordinario. El RP no prevé ninguna subdivisión específica de esta modalidad de vida, pese a ser la forma en la que cumplen la pena la mayor parte de los condenados en España ${ }^{15}$. Ello conduce a que todos los clasificados en ese grado deban someterse a las mismas condiciones de vida: las dispuestas en los arts. 76 a 79 RP. La ausencia de sub-regímenes dificulta la adaptación de este régimen a las necesidades del tratamiento, en particular, a la posible evolución que pueda producirse mientras el interno se encuentra clasificado en ese grado. Únicamente, tal y como se expondrá a continuación, ello podrá resultar posible a través de la aplicación de lo dispuesto en los arts. 117 RP y 100.2 RP.

\subsection{La previsión del art. 117 RP: salidas al exterior} para cumplir un programa de atención especializada para los clasificados en segundo grado ${ }^{16}$

Con la finalidad de ejecutar de modo flexible la pena, en supuestos de penados clasificados en segundo grado, el RP incorpora la posibilidad de acordar salidas al exterior para cumplir con un programa de atención especializada (art. 117 RP). De ese modo se alteran, aunque no de forma substancial, las condiciones comunes de cumplimiento del régimen

15 Vid. infra los datos de cumplimiento en segundo grado (en régimen ordinario) a nivel nacional (también en Cataluña) en el apartado IV dedicado a los datos de cumplimiento en España. Tal y como puede comprobarse en la Tabla 1, entre un 70 y el $75 \%$ de internos cumplen la mayor parte de su condena en segundo grado. Se refieren a ello IBÀÑEZ, A. y CID J. (2016:15) y IBÀÑEZ, A. (2019), "Progresar hacia el régimen abierto: la visión de los profesionales", en Revista Española de Investigación Criminológica, Artículo 7, número 17, p. 5. Señalan estos estudios que la mayor parte de los penados finalizan su condena en segundo grado, muchas veces sin haber obtenido ni el tercer grado ni la libertad condicional.

16 Se refiere expresamente a los art. 100.2 y 117 RP como dos vías adecuadas y compatibles que permiten flexibilizar el régimen común, entre otros el AAP de Barcelona (Sección 21ª), n. 564/2020 de 20 de marzo. 
ordinario (art. $102 \mathrm{RP}$ ), para permitir salidas al exterior siempre que cumplan determinadas requisitos: i) que el interno presente un perfil de baja peligrosidad ${ }^{17}$ y ii) no presente riesgo de quebrantamiento de condena.

De concurrir esos presupuestos se permite que los internos acudan de forma regular u ocasional a una institución exterior para cumplir con un programa concreto de atención especializada, siempre que éste se considere necesario para su tratamiento y reinserción social. Generalmente se acuerdan para llevar a cabo un programa de carácter psicosocial orientado a mejorar las capacidades de los internos y a abordar aquellos déficits específicos que puedan haber influido en su comportamiento delictivo (art. 110.2 RP) ${ }^{18}$.

En esos supuestos, el tratamiento a cumplir fuera del Centro deberá haber sido planificado por la Junta de Tratamiento, el interno deberá consentirlo y habrá de comprometerse a observar el régimen de vida de la institución exterior a la que acudirá. Además, para poder ser acordado, las salidas al exterior (puntuales o regulares) no deberán requerir de controles personales por parte de los miembros de los Cuerpos y Fuerzas de Seguridad. Las salidas deberán ser autorizadas por el Centro Directivo o por el Juez de Vigilancia Penitenciaria (en adelante JVP), dependiendo de si éstas son puntuales o diarias.

17 Para valorar la peligrosidad baja y el reducido riesgo de fuga vid. los criterios empleados en Auto AP Barcelona (Sección 21 $1^{\mathrm{a}}$ ) n.402/2020 de 27 de febrero 2020.

Sobre el valor predictivo del RisCanvi, instrumento empleado por la Administración catalana, para estimar el riesgo de quebrantamiento de un permiso, en relación con otros empleados por la Administración penitenciaria vid., FÉREZ-MANGAS, D. y ANDRÉS-PUEYO, A. "Eficacia predictiva en la valoración del riesgo del quebrantamiento de permisos penitenciarios" en LA LEY Penal n ${ }^{\circ} 134$, septiembre-octubre 2018, N ${ }^{\circ} 134,1$ de sep. de 2018, pp. 1-14.

18 Esta previsión parece estar encaminada a permitir la implementación de alguno de los elementos que integran el "Programa de tratamiento", dispuestos en el art $110 \mathrm{RP}$. 
Con frecuencia este tipo de salidas (art. 117 RP) se conciertan para la realización de tratamientos de desintoxicación, terapias para delincuentes sexuales, programas especiales para discapacitados o incluso, en algunas ocasiones, para el tratamiento de otras dependencias, como la ludopatía ${ }^{19}$. En todos los casos se requiere, tal y como se desprende del RP, que el concreto tratamiento al que se va a someter al interno no pueda ser llevado a cabo en el propio Centro Penitenciario o, por su especificidad, deba completarse fuera de él. Es necesario que la Junta de Tratamiento lo supervise y que exista un convenio con la institución u ONG que lo implementa. Aunque son más escasas, también se autorizan salidas fuera del Centro, en base a lo dispuesto en el art. 117 RP, para llevar a cabo una actividad laboral o de formación profesional, como parte del tratamiento (art. 110.a) RP). Así, por ejemplo, se han autorizado salidas al exterior para realizar un taller de jardinería, para trabajar en un taller de una bodega de vinos (RAIMAT) ${ }^{20}$ o incluso para la realización de un programa/taller dirigido a mejorar las relaciones familiares, sociales y laborales ${ }^{21}$. También se suele utilizar esta vía para que los internos realicen actividades de voluntaria$\mathrm{do}^{22}$, como parte también del tratamiento. Sin embargo, no se ha considerado adecuado autorizar la salida de internos en régimen ordinario para llevar a cabo actividades formativas, como un curso de diseño y publicidad impartido por el INEM ${ }^{23} \mathrm{O}$ para asistir a una autoescuela, al no considerarse tratamiento, entendido en sentido estricto ${ }^{24}$.

19 AAP Barcelona (Sección $9^{\circ}$ ) n. 430/2007, de 20 de marzo.

20 AAP Lleida (Sección 1 ${ }^{\mathrm{a}}$ ), n.716/2002 de 25 de octubre.

21 AAP Valladolid (Sección 4a ) n. 68/2004 de 17 de febrero.

22 Vid AJVP de Valladolid de 17/09/2019, en el que el JVP estima el recurso y autoriza las salidas programadas del art. $117 \mathrm{RP}$ para realizar voluntariado, confirmado por la AP de Ávila en el AAP Ávila 257/2019 de 25/10/2019 y que se ha mantenido hasta su clasificación recientemente en tercer grado.

23 AAP Madrid (Sección 5a), n. 3279/2005 de 20 de octubre.

24 AAP Cantabria (Sección 1 ${ }^{\text {a }}$ ) n 94/2007 de 6 de marzo, donde señala que no forman parte del tratamiento y no son tampoco condición de ninguna oferta laboral. 
Este tipo de medida, dirigida a permitir que se cumplan elementos específicos del tratamiento fuera del Centro penitenciario, se acostumbra a acordar aún en supuestos de condenas por delitos graves ${ }^{25}$, por ejemplo, en delitos sexuales o de tráfico de drogas. En esos casos el adecuado cumplimiento del tratamiento externo del art. $117 \mathrm{RP}$ ha sido valorado positivamente para la concesión de permisos de salida ordinarios. No obstante, cuando la pena de prisión impuesta no es de larga duración, la regla se invierte, y sólo se suele autorizar la realización de estos tratamientos fuera del Centro sí el penado ya ha disfrutado, sin incidencias, de algún permiso.

Por último, señalar que esta previsión únicamente pude cubrir salidas diarias no superiores a 8 horas y finaliza una vez cumplido el tratamiento o si éste se incumple. Esto es, si se rompen las reglas acordadas para su realización en el exterior. En realidad, tal y como se señaló, las modificaciones de la vida en prisión que supone la aplicación de esta previsión son temporales y reducidas al cumplimiento específico de un tratamiento en sentido estricto. No cubre, como analizaremos a continuación, alteraciones básicas del régimen de vida propio del segundo grado.

25 Vid. AAP de Barcelona (Sección 21 a) n.339/209 de 11 de febrero en la que autoriza la realización de tratamiento psicológico en un centro externo a un condenado por delitos contra la libertad sexual que se encontraba cumpliendo una pena de 22 años de prisión, habiendo informado positivamente la Junta de Tratamiento y el JVP. También en un sentido similar AAP Barcelona (Sección 21 ${ }^{\mathrm{a}}$ ) n. 1955/2018 de 7 de diciembre, en la que se acuerda autorizar un permiso de salida ordinario a un interno al que se había aplicado lo dispuesto en el art. 117 RP y las salidas se habían realizado sin incidentes. Aunque en ese caso el condenado ya había cumplido las tres cuartas partes de la condena. 


\subsection{Condiciones legales para la aplicación del art.}

\subsection{RP}

Las figuras a las que me he referido hasta ahora han sido identificadas por la doctrina y la jurisprudencia como manifestaciones del principio de flexibilidad. Pero, lo cierto es que cuando se hace alusión al principio de flexibilidad, éste se asocia con lo dispuesto en el art. 100.2 RP. Este precepto autoriza el cumplimiento de la pena de prisión conforme a elementos que corresponden a regímenes de vida de distintos grados. Esto es, se permite la combinación de aspectos característicos de más de un grado cuando ello resulta imprescindible para dar cumplimiento al programa individualizado de tratamiento, entendido en sentido amplio (art. $110 \mathrm{RP})^{26}$. Esta figura posibilita que los internos clasificados en primer o segundo grado pueden cumplir la pena bajo un régimen de vida mixto, distinto al asignado a su clasificación, alterando la correlación entre grado y régimen regulada en los arts. 72.1 LOGP, 100.1 y $101 \mathrm{RP}^{27}$.

26 El concepto de tratamiento que acoge el RP ya no puede interpretarse en el sentido de tratamiento clínico, asociado únicamente a programas o técnicas cognitivo-conductuales dirigidas a incidir sobre los factores que llevaron al sujeto a delinquir, sino de un modo amplio. Tal y como dispone el art. 110 RP, en el concepto de Programa de Tratamiento tienen cabida desde actividades formativas, de instrucción, laborales y clínicas (art. 110.c). RP). También forman parte del tratamiento los contactos con el exterior como mecanismo idóneo de reinserción social. Vid. sobre este concepto amplio de tratamiento CERVELLÓ, V., (2005: 161).

27 La mayoría de los autores que se han ocupado de esta cuestión valoran positivamente su inclusión en el sistema penitenciario. Vid., entre otros, CERVELLÓ, V. (2016: 224) quien indica que esta previsión facilita la progresión y permite acortar la distancia entre grados. Señalan algunos autores que la incorporación del principio de flexibilidad a través de la previsión dispuesta en el art. 100.2 RP integra uno de los aspectos más novedosos del reglamento puesto que permite romper la rigidez de la distribución en grados. Vid. en este sentido, TAMARIT, JM et al. (2005), Curso de derecho penitenciario, $2^{\mathrm{a}}$ ed., Valencia: Tirant Lo Blanch, p. 265. Por su parte FERNANDEZ ARÉVALO, L y NISTAL BURÓN, J (2012: 462) consideran que el principio de flexibilidad puede conducir a la existencia de una cuarta modalidad de régimen, mixta o 
Con esta previsión se pretende evitar que el programa de tratamiento acordado para un interno resulte dificultado por las condiciones de vida ordinarias que se asignan al grado en el que ha sido clasificado. Pero, ante todo, supone el reconocimiento expreso del principio de flexibilidad al confirmar la voluntad del RP de situar el tratamiento en el epicentro del sistema. De este modo, se destaca que el régimen y las condiciones de vida son un medio y no un fin en sí mismo y se encuentran supeditadas al tratamiento y a la finalidad que lo guía; la reinserción social (art. 59 LOGP) ${ }^{28}$.

El RP deja en manos de la Administración Penitenciaria la decisión sobre la aplicación de este "régimen mixto", requiriendo únicamente una intervención posterior del JVP, que debe, en todo caso, confirmarlo o revocarlo ${ }^{29}$. Es el Equipo Técnico a través de la Junta de Tratamiento el que valora la situación del interno y acuerda cuáles son los elementos del tratamiento y qué condiciones de vida requieren para su implementación. Si, como consecuencia de esa valoración, la Administración Penitenciaria determina que las condiciones de vida propias del grado en el que está clasificado no resultan acordes a las necesidades de tratamiento, puede proponer cambios y aplicar elementos propios de otro régimen. De ese modo se otorgan a la Administración amplias facultades para valorar los elementos que integran el tratamiento y las condiciones de vida idóneas para cada interno. Esa discrecionalidad debe lógicamente ser empleada por la Administración respetando la legalidad y justificando su decisión.

variable, que vendría a completar los tres regímenes comunes. LEGANES, S. GÓMEZ, S. (2005: 66) destaca también la importancia de su inclusión en el RP por permitir reducir las limitaciones que imponen los grados para el tratamiento.

28 Vid. FERNANDEZ BERMEJO, D. (2013:432 y ss.).

29 A diferencia de la previsión contenida en el art. 117 RP, en estos supuestos se requiere siempre de la ulterior aprobación de la decisión por el JVP. 
Debe reconocerse que la Administración penitenciaria se ha profesionalizado. Los Equipos Técnicos, la Junta de Tratamiento y todos los profesionales que intervienen en la clasificación y en la determinación del programa individualizado de tratamiento son profesionales que utilizan, para la toma de decisiones, sus conocimientos expertos. Efectivamente, son ellos los que disponen de los instrumentos y la información necesaria para acordar tales medidas ${ }^{30}$. Esta discrecionalidad con la que cuenta la Administración podrá, como en toda decisión administrativa, ser fiscalizada judicialmente. El JVP y, en su caso, los tribunales (Audiencias Provinciales) deberán comprobar que la Administración ha llevado a cabo un juicio racional y lógico de la situación del interno, así como que la aplicación del art. 100.2 RP se ha llevado a cabo respetando los requisitos impuestos legalmen$t^{31}$. Además, debe tenerse en cuenta que el JVP es un órgano judicial especializado en materia penitenciaria, lo que lo hace especialmente competente para el examen de esa materia.

Se ha criticado, con razón, las escasas indicaciones que ofrece el Reglamento en aras a la determinación de las circunstancias que aconsejan la adopción de esta forma mixta de vida. El art. 100.2 RP indica únicamente que será el Equipo Técnico el que propondrá a la Junta de Tratamiento el modelo de ejecución que considera adecuado para que el interno cumpla su programa de tratamiento. El reglamento

30 Sobre la formación y capacitación de los profesionales que trabajan en los centros penitenciarios vid la información disponible en la web del Ministerio del Interior, Administración penitenciaria, accesible en: https://www.institucionpenitenciaria.es/es/web/home/administracionpenitenciaria/recursos-humanos/formacion-y-promocion.

31 Destaca FERNANDEZ BERMEJO, D. (2013:494) la necesidad de que se dé traslado al JVP de todo el expediente del interno y no sólo del Programa de tratamiento. Se hace eco, de este modo, de la petición formulada reiteradamente por los JVP, alegando que sólo de ese modo se podrá llevar a cabo una revisión de la corrección de la decisión administrativa con la información suficiente para ello. 
condiciona la decisión sobre la adopción de esas medidas de flexibilización a que ésta se "fundamente en un programa específico de tratamiento que de otra forma no pueda ser ejecuta$d o$ ". En este sentido, desde una perspectiva formal, tanto los JVP como los tribunales que conocen de estas situaciones en vía de recurso, exigen para su confirmación que exista una propuesta por parte de la Junta de Tratamiento en la que se hagan constar los siguientes extremos: 1) descripción del programa específico de tratamiento, 2) explicación de las razones por las que no se puede ejecutar de otro modo, 3) identificación de los elementos de otros grados que se combinan o incorporan ${ }^{32}$

Del tenor literal del art. 100.2 RP se infiere que se trata de una iniciativa que debe correr a cargo de la propia Administración Penitenciaria ${ }^{33}$ y que ésta habrá de estar justificada por necesidades del tratamiento. No es posible la aplicación del régimen flexible, y así lo confirma abundante jurisprudencia, en vía de recurso como alternativa a la no progresión en grado, si la Administración penitenciaria no ha sido quien la ha propuesto ${ }^{34}$.

32 Se refiere a estos elementos JUANATEY DORADO, C. (2013), Manual de derecho penitenciario, $2^{\mathrm{a}}$ Ed, Madrid: Iustel, p. 128.

33 Aunque esta cuestión también ha sido controvertida y algunas Audiencias Provinciales, en concreto la de Madrid, habían considerado que podía proponerse a la Administración penitenciaria su aplicación, aunque ésta no hubiera tomado la iniciativa. Sin embargo, esta postura descayó y por regla general la petición subsidiaria de aplicación del 100.2 RP cuando no se logra la progresión al tercer grado es negada por la mayoría de las AP y JVP.

34 Sin embargo, de modo muy excepcional, el JVP Ávila confirmó la no progresión en grado e instó a la Administración a aplicar el régimen flexible. El auto -AJVP de Ávila de 5 de marzo de 2020 (caso URDANGARIN)- admite parcialmente el recurso interpuesto por el interno contra la decisión de la Administración penitenciario de mantenerlo en segundo grado. El JVP, en esa ocasión, pese a no existir propuesta de ampliación del art. 100.2 RP, acoge la petición del recurrente e insta a la Administración a aplicar un programa específico de tratamiento. Dicho auto fue recurrido por el MF que se opuso a la aplicación de ese 
Al margen de lo indicado, no se concreta normativamente ni qué elementos del tratamiento pueden requerir de una alteración de las condiciones de vida penitenciaria ni qué elementos del régimen de vida pueden quedar afectados. No se concretan las condiciones que justifican esa "excepcional" quiebra de la relación entre grado de clasificación y régimen.

La primera de las incógnitas a despejar se sitúa en la identificación de los supuestos a los que resulta aplicable. Esto es, si es posible la flexibilización negativa, dirigida a limitar el modo de vida usando elementos de un grado más

régimen flexible. La AP de Palma estimó el recurso y lo dejó sin efecto, alegando entre otros motivos, que su apreciación supondría adelantar el disfrute del régimen abierto únicamente por las condiciones especiales que presenta el Centro donde el interno cumple la pena (un centro de mujeres en el que cumple la condena de manera aislada). Junto a este argumento también consideró que impedían la aplicación del régimen flexible el tipo de delito cometido y la pena impuesta (5 años y 10 meses de prisión), en particular el hecho de no haber cumplido todavía la mitad de la pena. Interesante resulta también alguno de los argumentos esgrimidos por la magistrada que emite un voto particular, Dña. ROMERO ADÁN quien muestra su desacuerdo con la resolución, adoptada por mayoría, al considerar que las condiciones de vida que se proponen (en aplicación del art. 100.2 RP), no ponen en peligro los fines de prevención general y especial, máxime cuando se han impuesto además de penas privativas de libertad otras con carácter accesorio, de inhabilitación y prohibiciones de contratar y obtener subvenciones, que garantizan suficiente dichos fines.

Con posterioridad a esta resolución, la Administración penitenciaria -la JT del Centro de Ávila- propuso la aplicación de este régimen flexible, manteniendo el voluntariado autorizado por vía del art. 117 RP, y autorizando una salida de fin de semana al mes para acudir al domicilio de la madre. Esta decisión fue confirmada por el JVP en Auto de 13/08/2020. No obstante, la AP de Baleares, a petición del MF, revocó, una vez más, la aplicación del art. 100.2 RP, asumiendo de forma casi literal los argumentos empleados por el TS en el ATS 5672/2020 de 22 de julio de 2020, relativo a la causa especial /20907/2017, por el que se revoca la aplicación de ese régimen a FORCADELL. No obstante, recientemente la Administración penitenciaria y el JVP han resuelto su clasificación en tercer grado. Vid. Sobre esta última decisión https://elpais.com/espana/2021-01-20/el-juez-concede-el-tercer-grado-a-inaki-urdangarin.htm 
restrictivos, o únicamente la positiva, encaminada a ampliar la libertad de los penados y suavizar así la modalidad de vida que se asignan al régimen vinculado a la clasificación del interno. En relación con esta cuestión, aunque se ha discutido sí la combinación de elementos que corresponden a distintos grados (regímenes) podría realizarse con la finalidad de aproximar un grado superior a otro inferior (flexibilización negativa), finalmente esta posibilidad ha sido descartada ${ }^{35}$. No obstante, este tipo de limitaciones o restricciones de libertad podrían adoptarse al amparo de lo dispuesto en el art. 75 $\mathrm{RP}$, siempre que se respetaran las condiciones allí exigidas ${ }^{36}$.

Excluida la flexibilización negativa, los casos a los que podrá aplicarse el art. 100.2 RP quedan limitados a aquellos en los que se introducen elementos regimentales propios de un grado de clasificación superior, para conferir al penado un mayor espacio de libertad, aplicando condiciones de vida más benévolas o suavizadas. Así lo ha entendido la doctrina y ese es el ámbito al que lo ha vinculado la Administración Penitenciaria (nacional y catalana). Sin embargo, la falta de claridad de la previsión reglamentaria y los usos poco homogéneos del art. 100.2 RP hicieron necesaria la aprobación de la Instrucción 9/2007 de 21 de mayo, sobre clasificación y destino de penados. En la citada Instrucción se identifican los criterios básicos que deben guiar la adopción de decisiones sobre clasificación y se acotan, mínimamente, los supuestos incluidos en el precepto analizado.

35 Niega tal posibilidad por considerar que el Reglamento no puede entrar en contradicción con la LOGP, LEGANES, S. GÓMEZ, S. (2013:72).

36 Sobre los supuestos que habilitan para la aplicación de estas limitaciones vid. FEIXA EGEA, G. (2012), "Régimen penitenciario/clasificación y art. 75 del Reglamento Penitenciario. ¿Es el art. 75 RP un nuevo régimen de vida?", en Revista Electrónica de Ciencia Penal y Criminología, pp. 1-24. Consideran también una manifestación del principio de flexibilidad lo dispuesto en el precepto indicado, FERNANDEZ ARÉVALO/NISTAL (2012:46). 
Tal y como señala la Instrucción 9/2007, la previsión del art. 100.2 RP puede aplicarse a internos clasificados en primer grado con dos finalidades distintas. La primera, para preparar al interno para su paso al régimen ordinario favoreciendo, por ejemplo, la realización de actividades con penados que ya se encuentran clasificados en ese régimen, o incluso facilitando su traslado a otros módulos para realizar actividades comunes. Junto a estos supuestos se contempla también la posibilidad de flexibilizar el régimen de vida a internos a los que se ha aplicado una regresión de grado, pero presentan un perfil bajo de peligrosidad. En esos casos, para favorecer la vuelta al régimen ordinario en el menor tiempo posible, se autoriza a atemperar algunas variables regimentales $^{37}$.

También menciona la Instrucción la posibilidad de utilizar la previsión reglamentaria examinada para facilitar el tránsito del segundo al tercer grado. En estos supuestos la Instrucción únicamente precisa cuestiones puramente procedimentales y no entra a valorar, siquiera pone ejemplos, de los elementos del régimen que podrán combinarse para preparar al interno para su vida en semilibertad. Se limita a indicar que la decisión sobre la aplicación del 100.2 RP precisa de la remisión al Centro Directivo del programa específico de tratamiento sobre el que éste debe pronunciarse ${ }^{38}$.

37 Vid. la Instrucción 9/2007 sobre Clasificación y destino de penados, en la que se tratan las situaciones a las que se puede aplicar el principio de flexibilidad examinado, tanto para presos clasificados en primer grado (p.7) como para los clasificados en segundo. Sin embargo, son escasas las resoluciones que lo aplican a internos clasificados en primer grado. Como se expondrá en otro trabajo, se trata fundamentalmente de decisiones que suelen referirse a supuestos de terrorismo o narcotráfico.

38 Debe hacerse notar que el RP no establece obligación alguna de informar y someter a aprobación del Centro Directivo la adopción de las medidas dispuestas en el art. 100.2 RP. Algún autor ha defendido, sin embargo, que ello resulta coherente si se considera que este tipo de decisión debe equipararse a la clasificación en grado. En este sentido NISTAL BURÓN, J. (2020), "El principio de flexibilidad del artículo 100.2 
Establece que este régimen de vida mixto será ejecutivo de forma inmediata, sin necesidad de esperar a su confirmación por el JVP. Asimismo, subordina la duración de esta modificación regimental al periodo necesario para el cumplimiento del programa de tratamiento que lo justificó y, en todo caso, establece un periodo de revisión de 3 meses, inferior al que se requiere para revisar la clasificación en grado, que es de 6 meses.

Tal y como ya se ha destacado, ni el art. 100.2 RP ni tampoco la Instrucción 9/2007 señalan nada sobre las circunstancias concretas que deben concurrir para que la Junta de Tratamiento proponga una medida de esta clase. La citada Instrucción ventila esta cuestión con una genérica referencia a las necesidades de adaptar el régimen de vida al programa individualizado del interno, cuando la asignación de un grado -con la consiguiente atribución de un régimen de vida- no resulte apropiado. Se refiere únicamente a la "... conveniencia de aplicar un programa concreto de tratamiento adecuado a las características especificas del interno y encaminado a la consecución del fin de reinserción...".

del Reglamento Penitenciario. Algunas cuestiones competenciales. A propósito del Auto del Tribunal Supremo de 22 de julio de 2020. Causa especial 20907/2017", en Revista Aranzadi Doctrinal n. 11, diciembre de 2020 , pp. 136 y ss., en particular p.139. Este autor entiende que estamos ante una cuestión que afecta a la ejecución de la pena, con una trascendencia semejante a la de la clasificación. A partir de esta consideración reconoce que el órgano judicial competente para conocer del recurso de apelación contra los Autos de los Juzgados de Vigilancia Penitenciaria que resuelven sobre la aplicación de este régimen flexible corresponde al Tribunal Sentenciador. Avala así la decisión que sobre esta cuestión ha tomado el TS de 22 de julio de 2020, causa especial 20907/2017 (caso FORCADELL).

La interpretación que aquí se propone de la figura prevista en el art. 100.2 RP va en una dirección distinta. La aplicación del régimen flexible supone mantener el grado y modificar la forma de vida. De ese modo se crea un sub-régimen dentro del segundo grado. Mutatis mutandis se aproximaría más a aquella decisión por la que se acuerda que un interno que cumple en régimen abierto restringido pase a cumplir la pena conforme al art. 86.4 RP, y no a un cambio de grado. 
En principio, cabría inferir que la medida examinada debe adoptarse a partir del estudio de las circunstancias personales y particulares de cada interno y no puede vincularse con delitos o modalidades delictivas. El precepto examinado no establece ninguna limitación al respecto, con lo que es posible su aplicación a toda clase de condenados, por delitos de "calle", económicos o de cualquier naturaleza, también por delitos de terrorismo u otros a los que se conmine con penas graves $^{39}$. Probablemente en esos casos lo que variará serán las actividades tratamentales a llevar a cabo y/o posiblemente también el momento en el que se deba hacer la propuesta de aplicación de este régimen, por ejemplo, en el caso de condenas largas.

En cuanto a las necesidades tratamentales que justifican su adopción, al no imponerse tampoco ninguna limitación legal, debe interpretarse que podrá afectar a cualquiera de los elementos que integran el programa individualizado de tratamiento, en sentido amplio (arts. 59 LOGP y 110 RP), tanto los dirigidos a satisfacer necesidades laborales, formativas, psicosociales como de contacto con el exterior (necesidades de inserción social y familiar).

39 Aunque parece ser infrecuente, se ha acordado la aplicación de este régimen flexible a condenados por delitos graves. Así, por ejemplo, en el caso resuelto por el AAP de Barcelona 2212/2020 de 07/01/2020 en el que se confirma la aplicación del principio de flexibilidad a un condenado por un delito de asesinato y se indica que “... El tiempo de condena efectiva en relación a los años impuestos no son óbice para la concesión del régimen extraordinario cuando concurren sus condiciones y requisitos, como no sea desde la perspectiva retributiva que debe permanecer alejada de las consideraciones que hagamos, en las cuáles debe atenderse como prioridad prácticamente única a las necesidades de resocialización del interno. $Y$ desde esta perspectiva un riesgo medio de reincidencia violenta no explicado por la evolución tratamental del interno, como decimos totalmente favorable, no puede erigirse en un motivo hábil, por sí solo, para vedar su acceso al exterior y a un trabajo remunerado con el que atender el pago de la responsabilidad civil pendiente como medio de expresar su responsabilidad en los hechos y de aportar algo a la restauración (en la medida en que es posible) del daño causado a terceros con su conducta.". 
Por regla general, suele aplicarse a internos clasificados en segundo grado para facilitar la realización de una actividad laboral en el exterior, "del tipo que sea"40. Entiendo que esta medida podría resultar también adecuada para condenados por delitos económicos o de corrupción. Sin embargo, en esos casos sería conveniente que la oferta laboral externa no coincidiera con la actividad en el marco de la cual se cometió el delito. En mi opinión, resultaría más apropiado que se vinculara con un ámbito profesional distinto o incluso podría sustituirse por la realización de una actividad solidaria en el exterior, para asumir así valores prosociales ${ }^{41}$. Esta última opción permitiría además evitar que los delincuentes poderosos (delincuentes de cuello blanco) volvieran al entorno laboral en el que cometieron el delito y/o se vieran beneficiados por las facilidades que su posición o poder les brinda para obtener una oferta de trabajo en el exterior.

También se suele acordar la aplicación del régimen flexible para permitir la realización de programas o actividades formativas y profesionalizadoras. Por último, se ha propuesto en algunas ocasiones, para que el interno pueda incrementar los "contactos con la sociedad o la familia". Sin embargo, son más escasos los supuestos en los que se concede exclusivamente por ese último motivo, esto es, para dar soporte a la familia, cuidados de parientes enfermos o para mantener espacios de "encuentro familiar" 42 . Podría decirse

40 Eso parece inferirse del análisis de la jurisprudencia, como se expondrá en otro trabajo todavía pendiente de publicación.

41 Este es, por ejemplo, el caso de un corrupto balear, condenado a una pena de 13 años, que realiza trabajos de voluntariado en "Caritas", vía 100.2 RP. Vid. El Periódico, 20/11/2020, "De la cárcel por corrupción a "valioso voluntario" de Cáritas", Disponible en: https://www.elperiodicodearagon.com/noticias/espana/carcel-corrupcion-valioso-voluntariocaritas_1445561.html

42 En este sentido AAP de Barcelona 10019/2019 de 24/04/2019, en la que se autoriza la modificación de horarios del 100.2 RP para llevar a cabo salidas laborales y ampliar los horarios de salida del centro a los sábados para permitir al interno estar con su esposa y sus hijos y, de ese 
que predominan los casos en los que se propone para que el interno cubra una oferta laboral en el exterior, como parte de la actividad resocializadora o como medio para facilitar la satisfacción de la responsabilidad civil, en aquellos casos en los que ésta no ha sido satisfecha o no lo ha sido en su totalidad ${ }^{43}$.

Tampoco precisa el art.100.2 RP los cambios regimentales que pueden tener cabida en este régimen de vida flexible. Tal sólo que esas modificaciones deben ser necesarias para dar cumplimiento al tratamiento. Ello significa que podrán alterarse cualquiera de las circunstancias dispuestas en los arts. 76 y ss. del RP. Esto es, cualquiera de los elementos que conforman el modo de vida en el régimen ordinario y abierto (art. 100.1 RP). Así, sería posible que se acordara desde la variación de los horarios, por ejemplo, para realizar actividades en el Centro o fuera de él (art. 113 RP), hasta la periodicidad o el momento en el que éstas se deben llevar a cabo; de forma continua u ocasional, diarios o de fin de semana. En definitiva, autoriza a alterar cualquiera de las condiciones de vida asignadas al primer o segundo grado con un límite: no podrán acordarse condiciones de vida idénticas, en todos los sentidos, a las que corresponden al grado en el que no se está clasificado.

Por último, la cuestión más problemática se encuentra en la determinación de los requisitos que debe cumplir el penado para acordar su mantenimiento en un grado (primero o segundo), pero con aplicación de modos de vida propios de otro superior. El art. 100.2 RP una vez más únicamente

modo, cumplir con sus obligaciones como padre y mantener espacios de encuentro familiar.

43 Vid AAP Barcelona 10010/2018 de 18/05/2018, en la que subraya que la falta de satisfacción de la responsabilidad civil no debe constituirse en un impedimento para acordar salidas laborales en el marco del art. 100.2 RP, incluso aunque éstas generalmente no guarden relación con el delito cometido. 
se refiere a las necesidades tratamentales. Debe interpretarse que podrá acordarse su aplicación cuando, valoradas las circunstancias personales y penitenciarios del interno, éste no merezca progresar en grado (art.106.2RP) pero, sin embargo, concurran factores que permiten afirmar que se ha producido una modificación positiva de algunos factores relacionados con su actividad delictiva. Esto es, cuando de la ponderación de los criterios generales para determinar la clasificación (art. 63 LOGP y 102.2 RP) se desprende un buen pronóstico, pero no suficiente para su progresión en grado. Sin duda, como ha destacado CERVELLÓ, los criterios que recoge la normativa penitenciaria para realizar esta valoración global son ambiguos y subjetivos, lo que dificulta el establecimiento de pautas clara en materia de clasificación y progresión ${ }^{44}$. Esta situación hace todavía más difícil concretar los elementos que deberán concurrir, o no, y su ponderación, a los efectos de decidir que un interno no puede progresar en grado, pero se

44 Entre los factores que suele valorarse para el mantenimiento o progresión en grado están: los rasgos de la personalidad (vinculados con la asunción de responsabilidad), y el historial individual y personal (incluye la reincidencia o la adicción a drogas), la duración de la pena, el medio al que retornará el condenado, su participación en actividades de tratamiento (aunque estas no son obligatorias 106.4 RP). Junto a estos elementos suelen valorarse también otros a los que la ley no se refiere como: la lejanía del cumplimiento de la condena, la ausencia de permisos o las causas pendientes. Sobre esta cuestión vid. Críticamente CERVELLÓ, V., (2005: 182 y ss.).

Más recientemente JUANATEY, C. (2017:145) plantea la necesidad de adecuar la valoración y ponderación de estos elementos a la las especiales características que presentan los delincuentes de cuello blanco. De ese modo, sugiere la autora, se podría evitar que algunos de los factores a valorar en la progresión en grado o para la obtención de permisos, puedan privilegiar a esta clase de delincuentes. Sin embargo, esa ponderación y adaptación de los factores no puede llevar a tomar decisiones automáticas ni a bloquear el acceso a ellos, únicamente a ponderarlos adecuadamente. No sé si las razones retributivas y de prevención general podrá siempre primar en esos casos sobre otro tipo de finalidades, como las de prevención especial positiva. Quizá lo más conveniente sea siempre examinarlo en cada caso. 
le puede aplicar este régimen flexible. No obstante, una vez negada la posibilidad de progresar en grado, si se acreditan y justifican avances en el tratamiento, ello debería determinar la adopción de un nuevo PTI en el que podría resultar adecuado un cambio parcial de régimen para adaptarlo a la evolución de penado, en el sentido de lo dispuesto en el art. 100.2 RP.

Mantener que, para acordar el cumplimiento conforme a lo dispuesto en el art. 100.2 RP, el penado debe cumplir todos los requisitos que permiten su progresión en grado, supone anular su eficacia. Una interpretación en este sentido de la previsión examinada conculcaría, en mi opinión, lo dispuesto en el art. 72.3 LOGP en el que se establece que "En ningún caso se mantendrá a un interno en un grado inferior cuando por la evolución de su tratamiento se haga merecedor a su progresión". Si un interno merece ser clasificado en segundo o tercer grado no será posible mantenerlo en un grado inferior y aplicar el régimen flexible para evitar su clasificación bajo un régimen de vida más permisivo. En esos casos, difíciles de determinar objetivamente, la progresión es obligatoria y no puede utilizarse el art. 100.2 RP para retrasarla. No puede exigirse, como hace algún tribunal, que el interno cumpla todos los requisitos del tercer grado para confirmar la aplicación del principio de flexibilidad del art. 100.2 RP ${ }^{45}$.

En definitiva, a partir de lo que dispone el RP, debe interpretarse que para su aplicación se requiere que el interno cumpla los requerimientos para ser clasificado en primer o segundo grado. Su ámbito de aplicación quedaría básicamente circunscrito a aquellos casos en los que el penado no

45 Vid. en este sentido, entre otras, AAP de Burgos de 614/2018 de 27/06/2018, AAP de Burgos de 20/08/2019 donde indica que, si no existen motivos para progresar al interno a tercer grado, tampoco es posible la aplicación del régimen flexible del art. 100.2 RP. Vid también AAP de Bilbao 1330/2019 de 18/07/2019, AAP de Burgos 196/2019 de 26/02/2019. Algunos autores se refieren a este régimen como un "tercer grado encubierto". También parece asumir esta posición el ATS de 22 de julio de 2020, causa especial 20907/2017 (Caso FORCADELL). 
reúne alguna de las condiciones para ser clasificado en segundo grado y debe, por tanto, permanecer en régimen cerrado, y a aquellos otros en los que el interno debe mantenerse en segundo grado por no cumplir los requisitos para progresar al tercero (102.2 RP).

Interpretado de este modo, el régimen flexible podría cumplir una doble función. De un lado permitiría preparar al interno para progresar eventualmente en grado, facilitando su adaptación a la vida en semilibertad y ofreciéndole la posibilidad de corregir o eliminar los déficits que impiden su progresión en grado ${ }^{46}$. De otro, posibilitaría la creación de un sub-régimen dentro del régimen ordinario para el conjunto de internos que cumplen la pena clasificados en segundo grado. De este modo se favorecería la flexibilización de sus condiciones de vida y se facilitaría un mayor contacto de éstos con la comunidad, a través de su inserción laboral, profesional y social. En esos casos, el régimen del art. 100.2 RP se asemejaría al que corresponde al tercer grado común o restringido, aunque manteniendo otros elementos propios del régimen ordinario. Además, esta previsión permitiría también que los internos que cumplen su pena en primer grado, cuando hayan experimentado mejorías en su tratamiento, puedan compartir,

46 Vid. Sobre los factores que dificultan la progresión en grado y la necesidad de buscar estrategias que permitan acceder a los internos, clasificados en segundo grado, al mercado laboral y a la comunidad para facilitar su reinserción y quizá reducir así la tasa de reincidencia de los que terminan su condena en segundo grado, en régimen ordinario, PEDROSA, A. (2019). “AA quién dejamos atrás? Explorando los obstáculos de la progresión penitenciaria” en Revista Española de Investigación Criminológica. Artículo 7, Número 17, pp.15 y ss. Señala este autor que entre los factores que dificultan la progresión en grado y, por tanto, la salida progresiva de los internos clasificados en segundo grado, se encuentran: la condición de extranjero, la duración de la condena, haber cometido un delito violento, haber sufrido una revocación de grado, no haber satisfecho la responsabilidad civil, tener expedientes disciplinarios, o haber incumplido el programa de tratamiento. Algunas de ellas, influyen de forma relevante para la no progresión, y sitúan a algunos internos en una clara situación de desventaja (2019:5, 15 y 16). 
por ejemplo, espacios y vida con clasificados en régimen ordinario, creando un nuevo espacio regimental adecuado para sus necesidades tratamentales, pero manteniendo otros elementos propios del primer grado.

La valoración que de esta figura han realizado los autores que se han ocupado de ella ha sido positiva, en la línea de lo aquí defendido. En efecto, la mayoría de ellos/ as ha destacado su utilidad como complemento de los tres regímenes existentes ${ }^{47}$. La doctrina ha consideran que permite soslayar las posibles limitaciones que imponen los grados al tratamiento ${ }^{48}$, posibilitando la adaptación del régimen de vida para conseguir que éste sea los más individualizado posible ${ }^{49}$. Sin embargo, se han mostrado también preocupados por la indeterminación en las condiciones de aplicación de este régimen mixto ${ }^{50}$. Tal y como indica FERNANDEZ BERMEJO, su falta de taxatividad puede haber favorecido un uso discrecional y, en ocasiones, arbitrario del mismo. Tal y como ha señalado este autor es posible que haya ofrecido una cobertura idónea para retrasar la clasificación en tercer grado de internos que podrían haberla obtenido, impidiendo injustificadamente su progresión. En este mismo sentido se pronuncia también CERVELLÓ. Señala esta autora que el recurso a la aplicación de este régimen mixto puede haber evitado o retrasado la aplicación del tercer grado restringido del art. $82 \mathrm{RP}$, pudiendo haberse hecho un uso arbitrario y discriminatorio por parte de la Administración Penitenciaria y las instancias judiciales ${ }^{51}$.

47 Vid. FERNANDEZ ARÉVALO, L y NISTAL BURÓN, J (2012:462).

48 Vid. LEGANES, S. GÓMEZ, S. (2005:66).

49 Vid. FERNANDEZ BERMEJO, D. (2013:493).

50 Vid. CERVELLÓ DONDERIS, V. (2005:176 y 177) Aunque también esta autora ha valorado muy positivamente su existencia, sin embargo, demanda una mayor taxatividad y su inclusión en la LOGP. Vid. también LEGANES GÓMEZ, S. (2005:494) y FERNANDEZ BERMEJO, D. (2013:493 y ss.). Todos ellos critican la inseguridad jurídica que genera la falta de concreción del art. 100.2 RP.

51 Vid. CERVELLO, V. (2005:177), CERVELLÓ, V. (2016: 224). 
Quizá el análisis de los datos penitenciarios sobre la aplicación del art. 100.2 RP permita arrojar algo de luz, o cuanto menos identificar, cómo se está empleando. Veamos a continuación qué información nos ofrecen esos datos.

\subsection{Algunos datos relativos a la aplicación del art. 100.2RP en España (2010-2019)}

Como es sabido, la competencia en materia de ejecución de penas es ejercida por el Estado que es quien gestiona los Centros penitenciarios de todo el territorio nacional, salvo los catalanes y recientemente los vascos. Cataluña ha sido durante mucho tiempo la única Comunidad Autónoma que ejerce efectivamente la competencia ejecutiva en materia penitenciaria, aunque también la tiene atribuida el País Vasco, pero hasta la fecha no la había ejercido ${ }^{52}$. Esta situación obliga a tomar en consideración los datos catalanes, puesto que las decisiones en materia de 100.2 RP se adoptan en primera instancia desde la Administración penitenciaria y es posible que existan diferencias entre la política penitenciaria catalana y la del resto del Estado.

Para indagar sobre la realidad de la aplicación del régimen flexible he analizados los datos nacionales publicados por el Ministerio de Interior ${ }^{53}$ y los facilitados por la Dirección General de Ejecución Penal y Reinserción Social, Secretaría General de Instituciones Penitenciarias ${ }^{54}$. Los datos de la Administración penitenciaria catalana se han obtenido a partir de los publicados por la Conselleria de Justícia de

52 Vid. ampliamente sobre esta cuestión y sobre la singularidad de la política penitenciaria catalana TAMARIT SUMALLA, JM. (2026), "El sistema penitenciario catalán: fundamento y ejercicio de la competencia", en Revista d'Estudis Autonòmics i Federal, Presidencia Generalitat de Catalunya, p. 1 y ss. y 19 y ss.

53 Disponibles en http://www.interior.gob.es/web/archivos-y-documentacion/398.

54 Agradezco la pronta y eficaz colaboración de la Dirección General a la hora de facilitarme todos los datos relativos a la aplicación del art. 100.2 RP. 
la Generalitat ${ }^{55}$. Se han examinado los años comprendidos entre 2010 y 2019, aunque en relación con alguna cuestión se han incluido informaciones referentes al 2020. A continuación, se examinarán primero los datos a nivel nacional, luego los datos a nivel catalán y finalmente se llevará a cabo una comparación entre las dos administraciones.

\section{A. Datos a nivel nacional}

De los datos a los que se ha tenido acceso, a nivel nacional pueden inferirse las siguientes conclusiones:

1st. El número de internos que, en toda España (Cataluña incluida) cumple su condena según el régimen del art. 100.2 RP resulta significativo. Como puede observarse en las siguientes tablas ( 1 y 2 ), supera con creces el de aquellos que la cumplen en primer grado y, pese a ser un simple régimen de cumplimento, alcanza también un porcentaje destacable del total de los penados (entre el 3 y el $4 \%$ de internos clasificados en los tres grados que cumplen la pena en el centro penitenciario).

55 Disponibles en Departament de Justícia de la Generalitat de Catalunya (Serveis penitenciaris: http://justicia.gencat.cat/ca/departament/Estadistiques/serveis_penitenciaris y dades estadístiques: http://www.gencat. cat/justicia/estadistiques_serveis_penitenciaris/9_pob.html. 
Tabla 1: Clasificación de la población reclusa en España (*) (valores absolutos y porcentuales)

\begin{tabular}{|c|c|c|c|c|c|c|c|c|c|c|}
\hline & 2010 & 2011 & 2012 & 2013 & 2014 & 2015 & 2016 & 2017 & 2018 & 2019 \\
\hline \multirow{2}{*}{$1^{\mathrm{er}}$ Grado } & 1098 & 998 & 1100 & 1138 & 1103 & 1054 & 1047 & 1011 & 990 & 905 \\
\hline & $2,1 \%$ & $1,9 \%$ & $2,2 \%$ & $2,2 \%$ & $2,2 \%$ & $2,2 \%$ & $2,2 \%$ & $2,2 \%$ & $2,2 \%$ & $2,0 \%$ \\
\hline \multirow{2}{*}{$2^{\circ}$ Grado } & 42252 & 40501 & 40671 & 41373 & 41241 & 39705 & 37944 & 36639 & 35726 & 35520 \\
\hline & $80 \%$ & $79 \%$ & $80 \%$ & $81 \%$ & $81 \%$ & $81 \%$ & $81 \%$ & $81 \%$ & $80 \%$ & $80 \%$ \\
\hline \multirow{2}{*}{$3^{r}$ Grado } & 9731 & 9701 & 9083 & 8715 & 8487 & 8131 & 7738 & 7683 & 7801 & 8047 \\
\hline & $18 \%$ & $19 \%$ & $18 \%$ & $17 \%$ & $17 \%$ & $17 \%$ & $17 \%$ & $17 \%$ & $18 \%$ & $18 \%$ \\
\hline $\begin{array}{l}\text { Total } \\
(* *)\end{array}$ & 53081 & 51200 & 50854 & 51226 & 50831 & 48890 & 46729 & 45333 & 44517 & 44472 \\
\hline
\end{tabular}

(*) Incluye Cataluña

(**) En el total no se computan los que cumplen la pena en libertad condicional o fuera del Centro penitenciario ni los internos sin clasificar ni los preventivos.

Tabla de elaboración propia a partir de los datos ofrecidos por la Dirección General de Ejecución Penal y Reinserción Social, Secretaría General de Instituciones Penitenciarias y de los datos extraídos de la web del Ministerio del Interior. Disponibles en: http://www.interior.gob.es/web/archivos-y-documentacion $/ 398$

Tabla 2: Aplicación del art. 100.2 RP en España (*) (valores absolutos y porcentuales) $\begin{array}{llllllllll}2010 & 2011 & 2012 & 2013 & 2014 & 2015 & 2016 & 2017 & 2018 & 2019\end{array}$

\begin{tabular}{|ccccccccccc|}
$\begin{array}{c}\text { Art. } \\
\mathbf{1 0 0 . 2 ~ R P}\end{array}$ & 1982 & 1813 & 1609 & 1597 & 1984 & 1831 & 1894 & 1769 & 1747 & 1367 \\
$\begin{array}{c}(* *) \\
\text { Total }\end{array}$ & $3,70 \%$ & $3,50 \%$ & $3,20 \%$ & $3,10 \%$ & $3,90 \%$ & $3,70 \%$ & $4,10 \%$ & $3,90 \%$ & $3,90 \%$ & $3,10 \%$ \\
\cline { 2 - 10 } & $\mathbf{5 3 0 8 1}$ & $\mathbf{5 1 2 0 0}$ & $\mathbf{5 0 8 5 4}$ & $\mathbf{5 1 2 2 6}$ & $\mathbf{5 0 8 3 1}$ & $\mathbf{4 8 8 9 0}$ & $\mathbf{4 6 7 2 9}$ & $\mathbf{4 5 3 3 3}$ & $\mathbf{4 4 5 1 7}$ & $\mathbf{4 4 4 7 2}$ \\
\hline
\end{tabular}

(*) Incluye Cataluña

(**) Estos internos están clasificados en primer grado y, en su mayoría, en segundo.

Tabla de elaboración propia a partir de los datos ofrecidos por la Dirección General de Ejecución Penal y Reinserción Social, Secretaría General de Instituciones Penitenciarias y de los datos extraídos de la web del Ministerio del Interior. Disponibles en: http://www.interior.gob.es/web/archivos-y-documentacion/398

2nd. En cuanto a la tendencia de uso, debe decirse que la evolución detectada en los años examinados revela cierta estabilidad en la aplicación del art. 100.2 RP, con 
una tendencia a la baja, algo más acentuada en 2019 (Grafico 1).

Gráfico 1: Aplicación del art. 100.2 RP en España (tendencia)

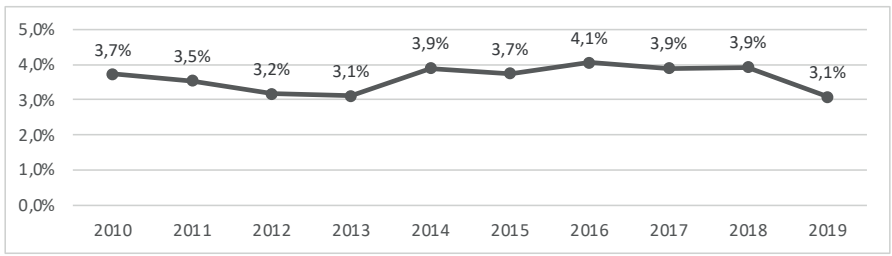

Gráfico de elaboración propia a partir de los datos facilitados por la Dirección General de Ejecución Penal y Reinserción social, Secretaría General de Instituciones Penitenciarias.

3rd. Los supuestos a los que se aplica con mayor frecuencia lo dispuesto en el artículo examinado son los que corresponden a internos clasificados en segundo grado. Los datos a nivel nacional muestran que la aplicación de este régimen de vida mixto o combinado se emplea con mucha menos frecuencia a internos clasificados en primer grado y sometidos a régimen cerrado (Tabla 3).

Tabla 3: Aplicación del art. 100.2 RP en España (*) según el grado de clasificación

\begin{tabular}{|ccccccccccc|}
\hline & $\mathbf{2 0 1 0}$ & $\mathbf{2 0 1 1}$ & $\mathbf{2 0 1 2}$ & $\mathbf{2 0 1 3}$ & $\mathbf{2 0 1 4}$ & $\mathbf{2 0 1 5}$ & $\mathbf{2 0 1 6}$ & $\mathbf{2 0 1 7}$ & $\mathbf{2 0 1 8}$ & $\mathbf{2 0 1 9}$ \\
\hline $\begin{array}{l}\text { De 1 } \\
\text { grado }\end{array}$ & 77 & 102 & 127 & 80 & 73 & 80 & 53 & 55 & 67 & 142 \\
\hline $\begin{array}{l}\text { De 2 } \\
\text { grado }\end{array}$ & 1905 & 1711 & 1482 & 1517 & 1911 & 1751 & 1841 & 1714 & 1680 & 1225 \\
\hline Total & $96,10 \%$ & $5,60 \%$ & $7,90 \%$ & $5,00 \%$ & $3,70 \%$ & $4,40 \%$ & $2,80 \%$ & $3,10 \%$ & $3,80 \%$ & $10,40 \%$ \\
\cline { 2 - 8 } & 1982 & 1813 & 1609 & 1597 & 1984 & 1831 & 1894 & 1769 & 1747 & 1367 \\
\hline
\end{tabular}

(*) Incluye Cataluña.

Tabla de elaboración propia a partir de los datos facilitados por la Dirección General de Ejecución Penal y Reinserción social, Secretaría General de Instituciones Penitenciarias. 
4th. El mecanismo previsto en el art. 100.2 RP y el dispuesto en el art. $117 \mathrm{RP}$ no tienen la misma incidencia penitenciaria. El volumen de internos a los que se autorizan salidas al exterior para cumplir un programa especializado de tratamiento psicológico o clínico es muy inferior al de los internos que viven conforme al régimen flexible, tal y como se desprende del Gráfico 2. Además, aunque a nivel nacional el empleo de ambos mecanismos de flexibilización del régimen de vida para los clasificados en segundo grado ha disminuido, el descenso en la aplicación del art. 117 RP ha sido substancialmente mayor. Esa paulatina disminución, más acentuada en los tres primeros años (entre 2010 y 2013), ha conducido a unas cifras de implementación de esta figura muy reducidas.

Gráfico 2: Aplicación del art. 117 RP y del art. 100.2 RP en España, tendencias (incluye Cataluña)

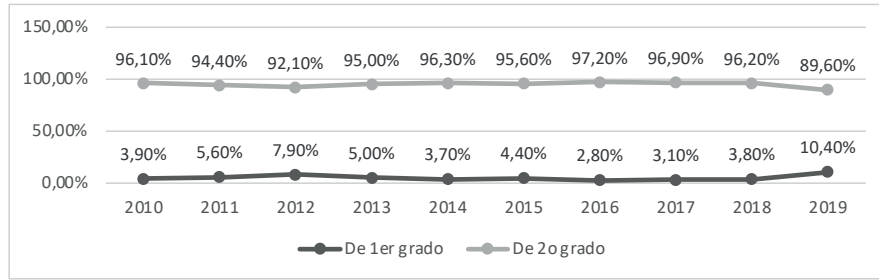

Gráfico de elaboración propia a partir de los datos facilitados por la Dirección General de Ejecución Penal y Reinserción Social, Secretaría General de Instituciones Penitenciarias.

5th. Desde una perspectiva de género, el porcentaje de mujeres a las que se aplica el régimen flexible es superior al de hombres (Grafico 3). Además, se constata que la aplicación de la figura estudiada a hombres y mujeres también presenta perfiles distintos. Es decir, mientras la evolución en hombres es claramente descendiente, la tendencia en su aplicación a mujeres es constante, 
con una ligera tendencia a la baja. Esta situación resulta coherente si se tiene en cuenta que también es frecuente que el porcentaje de mujeres que acceden al tercer grado, en sus distintos regímenes, suele ser superior al de hombres ${ }^{56}$.

Gráfico 3: Aplicación en España del art. 100.2 RP por sexos (2012 a 2019) ${ }^{57}$

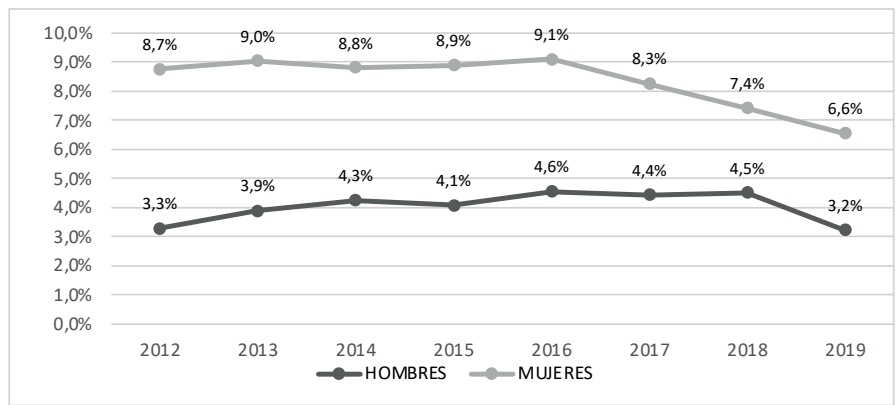

Gráfico de elaboración propia a partir de los datos facilitados por la Dirección General de Ejecución Penal y Reinserción Social, Secretaría General de Instituciones Penitenciarias.

\section{B. Datos a nivel catalán}

A nivel catalán, los datos que brinda la Administración penitenciaria son, como veremos a continuación, algo distintos de los nacionales. Las tendencias en materia de ejecución de penas, por lo menos en algunos aspectos, como el examinado, presentan diferencias en el siguiente sentido:

56 Vid. Algunas explicaciones a esta diferencia por lo que respecta al tercer grado y a la libertad condicional CAPDEVILA, M. (2019: 175 y ss.). Destacan estos autores que las características personales, sociales y el tipo de delitos cometido podrían explicar esta diferencia.

57 Sólo se dispone de los datos sobre el total de clasificados en segundo grado por sexos a partir de 2012. Disponibles en: http://www.interior. gob.es/web/archivos-y-documentacion/398 
1st. El número de internos a los que se les aplica el régimen del art. 100.2 RP en Cataluña es también significativo. Respecto al total de internos clasificados oscila entre el 3\% y el 7\% (Tabla 5).

Tabla 4: Clasificación de la población reclusa en Cataluña (valores absolutos y porcentuales)

\begin{tabular}{|c|c|c|c|c|c|c|c|c|c|c|}
\hline & 2010 & 2011 & 2012 & 2013 & 2014 & 2015 & 2016 & 2017 & 2018 & 2019 \\
\hline \multirow{2}{*}{$1^{\text {er }}$ Grado } & 231 & 203 & 224 & 224 & 179 & 173 & 181 & 138 & 164 & 134 \\
\hline & $3 \%$ & $2 \%$ & $3 \%$ & $3 \%$ & $2 \%$ & $2 \%$ & $2 \%$ & $2 \%$ & $2 \%$ & $2 \%$ \\
\hline \multirow{2}{*}{$2^{\circ}$ Grado } & 6489 & 6477 & 6352 & 6494 & 6172 & 5939 & 5670 & 5448 & 5132 & 4989 \\
\hline & $76 \%$ & $76 \%$ & $77 \%$ & $78 \%$ & $77 \%$ & $78 \%$ & $78 \%$ & $76 \%$ & $74 \%$ & $74 \%$ \\
\hline \multirow{2}{*}{$3^{r}$ Grado } & 1843 & 1882 & 1717 & 1571 & 1616 & 1492 & 1451 & 1558 & 1661 & 1653 \\
\hline & $22 \%$ & $22 \%$ & $21 \%$ & $19 \%$ & $20 \%$ & $20 \%$ & $20 \%$ & $22 \%$ & $24 \%$ & $24 \%$ \\
\hline $\begin{array}{l}\text { Total } \\
(* *)\end{array}$ & 8563 & 8562 & 8293 & 8289 & 7967 & 7604 & 7302 & 7144 & 6957 & 6776 \\
\hline
\end{tabular}

(**) En el total no se computan los que cumplen la pena en libertad condicional o fuera del Centro penitenciario ni los internos sin clasificar ni los preventivos.

Tabla de elaboración propia a partir de los datos publicados por el Departament de Justícia de la Generalitat de Catalunya (Serveis penitenciaris: http:// justicia.gencat.cat/ca/departament/Estadistiques/serveis_penitenciaris y dades estadístiques: http://www.gencat.cat/justicia/estadistiques_serveis_penitenciaris/9_pob.html)

Tabla 5: Aplicación del art. 100.2 RP en Cataluña (valores absolutos y porcentuales)

\begin{tabular}{|l|cccccccccc|}
\hline & $\mathbf{2 0 1 0}$ & $\mathbf{2 0 1 1}$ & $\mathbf{2 0 1 2}$ & $\mathbf{2 0 1 3}$ & $\mathbf{2 0 1 4}$ & $\mathbf{2 0 1 5}$ & $\mathbf{2 0 1 6}$ & $\mathbf{2 0 1 7}$ & $\mathbf{2 0 1 8}$ & $\mathbf{2 0 1 9}$ \\
\hline $\mathbf{1 0 0 . 2} \mathbf{R P}$ & 487 & 389 & 295 & 295 & 264 & 297 & 314 & 441 & 415 & 480 \\
& $5,70 \%$ & $4,50 \%$ & $3,60 \%$ & $3,60 \%$ & $3,30 \%$ & $3,90 \%$ & $4,30 \%$ & $6,20 \%$ & $6,00 \%$ & $7,10 \%$ \\
$\begin{array}{l}\text { Total } \\
\text { internos } \\
(*)\end{array}$ & 8563 & 8562 & 8293 & 8289 & 7967 & 7604 & 7302 & 7144 & 6957 & 6776 \\
\hline
\end{tabular}

(*) En el total únicamente se computan los clasificados en los tres grados que cumplen la pena en el centro penitenciario, no los preventivos.

Tabla de elaboración propia a partir de los datos publicados por el Departament de Justícia de la Generalitat de Catalunya (Serveis penitenciaris: http:// justicia.gencat.cat/ca/departament/Estadistiques/serveis_penitenciaris y dades 
estadístiques: http://www.gencat.cat/justicia/estadistiques_serveis_penitenciaris/9_pob.html)

2nd. En el caso catalán además se constata que la tendencia en la aplicación de este régimen ha evolucionado al alza (Gráfico 4).

Gráfico 4: Aplicación del art. 100.2 RP en Cataluña (tendencia)

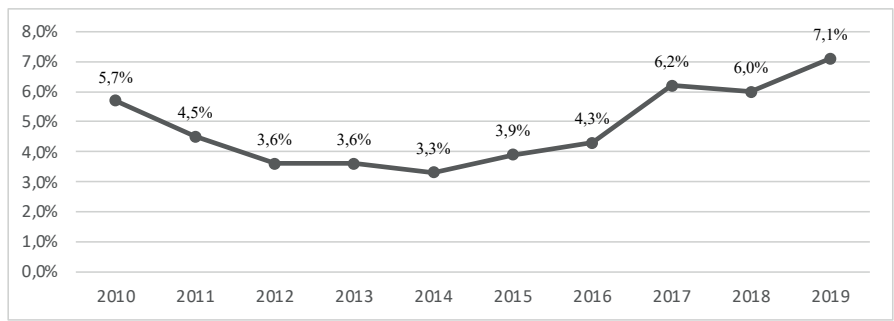

Tabla de elaboración propia a partir de los datos publicados por el Departament de Justícia de la Generalitat de Catalunya (Serveis penitenciaris: http:// justicia.gencat.cat/ca/departament/Estadistiques/serveis_penitenciaris y dades estadístiques: http://www.gencat.cat/justicia/estadistiques_serveis_penitenciaris/9_pob.html)

C. Comparación entre los datos de ambas Administraciones

1st. Los datos indican que el número de internos a los que se aplica el art. 100.2 RP en Cataluña es ligeramente superior al nacional. Oscila entre el 3,3 y el 7,1\%, mientras que el porcentaje sobre el total de clasificados a nivel nacional se mantiene en una horquilla de entre el 3,1 y el 3,7\%. 
Gráfico 5: Aplicación del art. 100.2 RP en España y en Cataluña

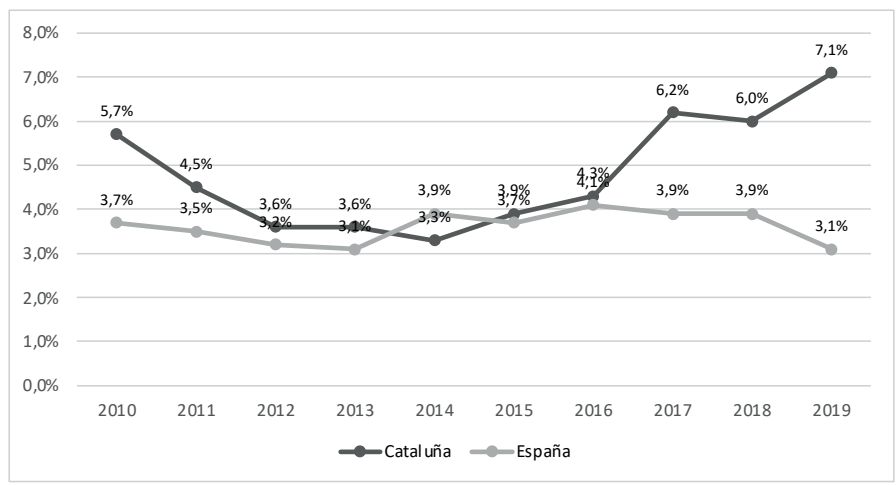

Gráfico de elaboración propia a partir de los datos publicados por el Departament de Justícia de la Generalitat de Catalunya (Serveis penitenciaris: http://justicia.gencat.cat/ca/departament/Estadistiques/serveis_penitenciaris y dades estadístiques: http://www.gencat.cat/justicia/estadistiques serveis penitenciaris/9 pob.html)

2nd. Los datos del Gráfico 5 revelan además que en Cataluña el uso de esta previsión reglamentaria se ha incrementado particularmente en los últimos tres años (2017 al 2019).

3rd.El porcentaje de internos que cumplen su pena en prisión clasificados en tercer grado es ligeramente superior en Cataluña. Las horquillas en las que se mueven ambas administraciones así lo demuestran: en Cataluña entre el 19 y el 24\% y en España entre el 17 y el 19\% (Gráfico 6). Además, la tendencia en Cataluña en la aplicación de este régimen es ascendente mientras que a nivel nacional se constata cierta estabilidad. 
Gráfico 6: Aplicación del tercer grado en España y en Cataluña

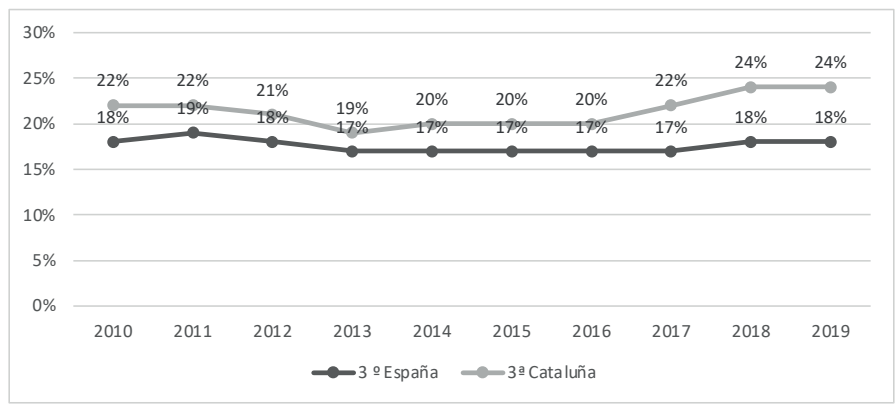

Gráfico de elaboración propia a partir de los datos publicados por la Dirección General de Ejecución Penal y Reinserción Social. Secretaría General de Instituciones Penitenciarias y los datos extraídos de la web del Ministerio del Interior Y de Cataluña. Disponibles en: http://www.interior.gob.es/web/ archivos-y-documentacion/398 y en la web de Departament de Justícia de la Generalitat de Catalunya Serveis penitenciaris: http://justicia.gencat.cat/ ca/departament/Estadistiques/serveis_penitenciaris y dades estadístiques: http://www.gencat.cat/justicia/estadistiques serveis penitenciaris/9 pob. $\underline{\mathrm{html}}$

4th.Los datos examinados parecen indicar que la Administración penitenciaria catalana se muestra ligeramente más favorable a autorizar el cumplimiento de la prisión otorgando un mayor grado de libertad. El porcentaje de internos a los que se les aplica el 100.2 RP y el de los que cumplen condena en tercer grado es superior en Cataluña. En definitiva, la Administración catalana parece más partidaria de adoptar regímenes de vida tendentes a ampliar el contacto del interno con el exterior ${ }^{58}$.

58 Esta es también la conclusión a la que llegan un grupo de investigadores del Área de Investigación y Formación en Ejecución Penal en Cataluña. Vid. CAPDEVILA, M. (2019:51). Quienes señalan que el porcentaje de población que cumple la pena en régimen de semilibertad (3er grado y libertad condicional) en Cataluña es superior al que lo hace en el resto de España. Sin embargo, en el estudio no se incluye el análisis de los condenados a los que se aplica el régimen aquí analizado, que también cumplen parcialmente la pena en la comunidad. 
En efecto, si comparamos la tendencia en la aplicación del régimen del art. 100.2 RP y la de los clasificados en tercer grado en Cataluña, se constata que en los tres últimos años el porcentaje de internos en régimen abierto ha aumentado y también lo ha hecho el porcentaje de los que cumplen la pena en régimen ordinario con aplicación del art. 100.2 RP (Gráfico 7).

Ello podría significar que entre el régimen flexible y el tercer grado existe una correlación. Es decir, que la Administración catalana está empleando el art. 100.2 RP para preparar, eventualmente, el paso al tercer grado. Si ello fuera así, nos encontraríamos con que, a mayor número de internos en régimen flexible, mayor número de internos que progresan al tercer grado. No obstante, para poder confirmar esta correlación deberíamos contar con los datos sobre el volumen de internos que progresan a tercer grado desde el 100.2 $\mathrm{RP}$, que desafortunadamente no están disponibles.

Gráfico 7: Aplicación del art. 100.2 RP y del tercer grado en Cataluña

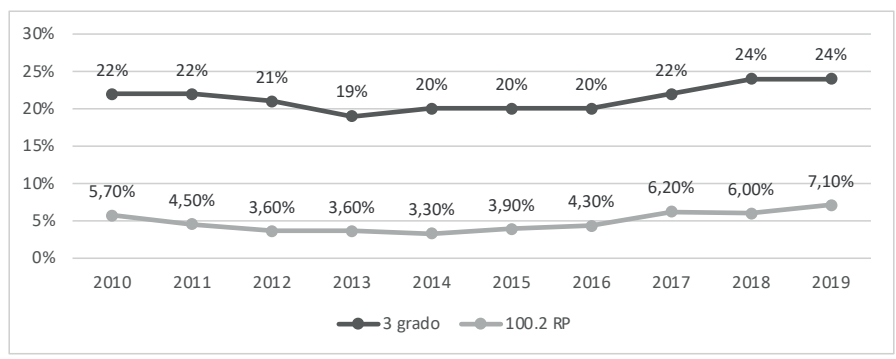

Gráfico de elaboración propia a partir de los datos publicados por el Departament de Justícia de la Generalitat de Catalunya (Serveis penitenciaris: http://justicia.gencat.cat/ca/departament/Estadistiques/serveis_penitenciaris y dades estadístiques: http://www.gencat.cat/justicia/estadistiques_serveis_penitenciaris/9_pob.html 
5th. Frente a esta tendencia, se constata que a nivel nacional tanto la aplicación del 100.2 RP como la aplicación del tercer grado se mantienen relativamente estables, con porcentajes más bajos que en Cataluña, como muestra el siguiente gráfico.

Gráfico 8: Aplicación del art. 100.2 RP y del tercer grado en España

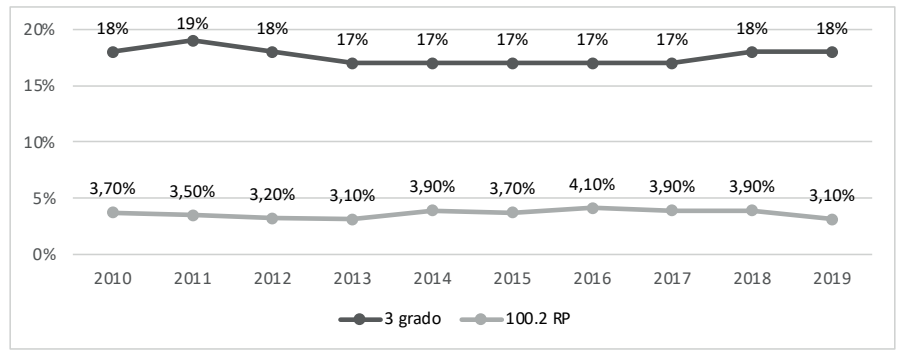

Tabla de elaboración propia a partir de los datos ofrecidos por la Dirección General de Ejecución Penal y Reinserción social. Secretaría General de Instituciones Penitenciarias y los datos extraídos de la web del Ministerio del Interior. Disponibles en: http://www.interior.gob.es/web/archivos-ydocumentacion/398

6th. Por último, aunque ello no guarde una relación directa con el objeto de estudio, de los datos analizados también se infiere que la aplicación del régimen abierto y sus distintas sub-modalidades de vida se lleva a cabo de modo distinto en una y otra Administración (Tablas 6 y 7).

Según se desprende de los datos, la mayor parte de los clasificados en tercer grado que cumplen la pena en centros penitenciarios catalanes lo hacen en el régimen común y en Unidades dependientes o según lo dispuesto en el art. 86.4 RP. Ello corroboraría que la política penitenciaria en Cataluña en estos últimos años ha sido algo más generosa a la hora de acordar formas 
de vida que implican un mayor grado de libertad y de cumplimiento en la comunidad (Tabla 6$)^{59}$.

Destacar, en relación con los datos de la Administración catalana de cumplimiento en tercer grado, que en 2020 la distribución entre los sub-regímenes ha variado, viéndose alterada probablemente por efecto de la pandemia. Los datos revelan que se ha incrementado notablemente el cumplimiento fuera del Centro penitenciario. En particular, ha aumentado substancialmente el número de internos a los que se aplica el art. 86.4 RP en detrimento del régimen abierto común (Tabla 6).

Tabla 6: Modalidades de cumplimiento del $3^{\text {er }}$ grado en Catalunya (incluye 2020)

\begin{tabular}{|cc|ccccc|ccccc|c|}
\hline \multicolumn{2}{|c|}{$\mathbf{2 0 1 0}$} & $\mathbf{2 0 1 1}$ & $\mathbf{2 0 1 2}$ & $\mathbf{2 0 1 3}$ & $\mathbf{2 0 1 4}$ & $\mathbf{2 0 1 5}$ & $\mathbf{2 0 1 6}$ & $\mathbf{2 0 1 7}$ & $\mathbf{2 0 1 8}$ & $\mathbf{2 0 1 9}$ & $\mathbf{2 0 2 0}$ \\
\hline $\begin{array}{c}\text { Art. 82 } \\
\text { (*) }\end{array}$ & 233 & 319 & 335 & 241 & 214 & 198 & 189 & 164 & 150 & 82 & $\mathbf{1 3 9}$ \\
$\begin{array}{c}\text { Régimen } \\
\begin{array}{c}\text { abierto } \\
\text { común }\end{array}\end{array}$ & 1.253 & 1.120 & 951 & 942 & 993 & 853 & 851 & 924 & 1.016 & 1.021 & $\mathbf{4 5 1}$ \\
$\begin{array}{c}\text { Unid } \\
\text { Depend. }\end{array}$ & 134 & 126 & 137 & 133 & 127 & 152 & 143 & 173 & 211 & 231 & $\mathbf{2 3 1}$ \\
\hline $\begin{array}{c}\text { Art. } \\
\mathbf{8 6 . 4} \\
\text { (**) }\end{array}$ & 223 & 317 & 294 & 255 & 282 & 289 & 268 & 297 & 284 & 319 & $\mathbf{7 8 2}$ \\
\hline
\end{tabular}

(*) Régimen abierto restringido

(**) Internos que cumple la condena en su domicilio con control telemático o de otro tipo.

Tablas de elaboración propia a partir de los datos publicados por el Departament de Justícia de la Generalitat de Catalunya (Serveis Penitenciaris: http://justicia.gencat.cat/ca/departament/Estadistiques/serveis_penitenciaris y Dades estadístiques: http://www.gencat.cat/justicia/estadistiques serveis penitenciaris/9 pob.html)

59 Esta conclusión no se ve alterada si se incluyen también los datos sobre libertad condicional en una y otra Administración. Vid. sobre la evolución de los internos en libertad condicional a nivel nacional y en Cataluña, CAPDEVILA, M. (2019: 52). 
Por el contrario, la Tabla 7 muestra como a nivel nacional la forma más frecuente de cumplir la pena en régimen abierto es la modalidad de vida del art. $82 \mathrm{RP}$, esto es, el régimen abierto restringido ${ }^{60}$. Parece que la administración penitenciaria española ha optado por un cumplimiento más aflictivo en el que los espacios de libertad quedan reducidos. Esta tendencia, sostenida en el tiempo, se ha vista parcialmente alterada en 2020 por un notable incremento de la aplicación del régimen del art. 86.4 RP, quizás influido también por la situación de pandemia. Ha aumentado el número de internos en el régimen del art. 86.4 $\mathrm{RP}$ y se ha reducido el de los que cumplen en tercer grado en régimen restringido y común.

En todo caso, ello no ha provocado un incremento de los internos clasificados en régimen abierto, que se ha mantenido. Únicamente se han redistribuido de modo distinto en los diferentes sub-regímenes que integran el tercer grado (Tabla 7).

Tabla 7: Modalidades de cumplimiento del $3^{\text {er }}$ grado en España (incluye 2020)

$\begin{array}{lllllllllll}2010 & 2011 & 2012 & 2013 & 2014 & 2015 & 2016 & 2017 & 2018 & 2019 & 2020\end{array}$

\begin{tabular}{cc|ccccc|cccc|c|}
\hline Art. 82 (*) & 7273 & 7773 & 6867 & 7755 & 7874 & 7575 & 6661 & 5964 & 5896 & 6394 & $\mathbf{4 7 5 0}$ \\
$\begin{array}{c}\text { Régimen } \\
\text { abierto } \\
\text { común }\end{array}$ & 2.911 & 2.913 & 2282 & 2335 & 2303 & 2188 & 2224 & 2188 & 2.094 & 2.214 & $\mathbf{1 4 6 5}$ \\
$\begin{array}{c}\text { Unid. } \\
\text { Depend. }\end{array}$ & 56 & 33 & 21 & 15 & 17 & 13 & 4 & 5 & 8 & 2 & $\mathbf{1 3}$ \\
$\begin{array}{c}\text { Art. 86.4 } \\
(* *)\end{array}$ & 650 & 576 & 406 & 434 & 462 & 394 & 338 & 344 & 377 & 381 & $\mathbf{1 7 4 5}$ \\
\hline
\end{tabular}

(*) Tercer grado restringido

(*) Internos que cumple la condena en su domicilio con control telemático o de otro tipo.

Tabla de elaboración propia a partir de los datos facilitados por la Dirección General de Ejecución Penal y Reinserción social.

60 Esto estaría señalando que el régimen más frecuente en el que se cumple la pena en tercer grado a nivel nacional es el restringido, mientras que en Cataluña es el que hemos denominado régimen abierto común. 


\section{Conclusiones}

De lo dicho hasta el momento sobre la aplicación del régimen flexible previsto del art. 100.2 RP se desprende que éste no ha sido utilizado para conferir privilegios, ni se ha vinculado a una determinada clase de delincuencia, como la económica o la relacionada con "los poderosos". Las sospechas que pudieran planear sobre esta modalidad de cumplimiento de la pena de prisión deben quedar despejadas a la vista de los datos examinados y de las condiciones a las que se somete su aplicación. Pero, sobre todo, el posible beneficio que también pudiera reportar la aplicación de este régimen a esos condenados no puede hacer perder de vista la finalidad asignada a esta previsión, que no es otro que la de corregir los posibles "desajustes" provocados por la correlación establecida entre grado de clasificación y régimen de vida. En particular, como se ha tratado de demostrar, en el caso del los clasificados en segundo grado.

Por el contrario, el objetivo asignado a la misma conduce a conclusiones claramente distintas que trataré de resumir a continuación. Así, en el presente estudio se parte de una constatación: la legislación penitenciaria establece una estrecha correlación entre el grado de clasificación y el régimen de vida (art. 72 LOGP), pudiendo ello provocar que, en ocasiones, el régimen que corresponde al grado de tratamiento asignado obstaculice el cumplimiento del tratamiento.

Esta indeseable consecuencia, contraria a los principios que inspiran el sistema de individualización científica, puede verse mitigada a través de la aplicación de mecanismos que posibiliten dotar de mayor "flexibilidad" al sistema de clasificación en grados. Con esta finalidad el RP incorpora diversas previsiones, entre ellas, el reconocimiento de la posibilidad de aplicar distintos sub-regímenes de vida, tanto para los clasificados en primer grado como en tercero. De ese modo se permite una mejor adaptación a las necesidades de tratamiento de los internos clasificados en estos dos grados. 
Sin duda, al ofrecerse a la Administración penitenciaria un número más elevado de modelos de vida, se facilita la selección del más acorde con las necesidades de tratamiento. Además, y ello se constata particularmente en el régimen abierto, el escalonamiento de los modos de vida -desde el más restrictivo hasta el más cercano a la libertad-permite valorar la evolución del penado y asignarle consecuencias positivas. Esto es, la progresiva asunción de mayores cuotas de libertad dentro de un mismo grado.

Entiendo que la ausencia de sub-regímenes aplicables a los clasificados en segundo grado dificulta el posible acomodo de las condiciones de vida a las necesidades del tratamiento, en particular, a la posible evolución positiva del interno mientras se encuentra clasificado en ese grado. Para salvar ese escollo, el RP contiene dos mecanismos dirigidos a facilitar la flexibilización, esencialmente, del régimen ordinario: los dispuestos en los arts. 117 y $100.2 \mathrm{RP}$.

Ambas previsiones se encaminan a "relajar" determinadas condiciones de vida en prisión. Su aplicación se dirige a facilitar la realización del programa de tratamiento (art. 110 RP). La primera, con un alcance muy limitado, permite llevar a cabo modificaciones regimentales, salidas al exterior, para el cumplimiento de un tratamiento específico (en sentido estricto). La segunda, con un alcance y consecuencias más amplias, autoriza el cumplimiento de la pena de prisión conforme a elementos que corresponden a regímenes de vida de distintos grados. Esto es, se permite la combinación de aspectos característicos de más de un grado cuando ello resulta imprescindible para dar cumplimiento al programa individualizado de tratamiento, entendido en sentido amplio (art. 110 RP), sin que se altere la clasificación en grado.

La interpretación que se ha mantenido del art. 100.2 RP permite asignar a esta previsión reglamentaria una doble función. De un lado puede emplearse para preparar al interno para progresar en grado, facilitando su adaptación 
a la vida en semilibertad y ofreciéndole la posibilidad de corregir o eliminar los déficits que impiden su progresión en grado. De otro, para crear un sub-régimen dentro del régimen ordinario, aplicable a internos clasificados en segundo grado, cuando éstos no cumplen las condiciones para vivir conforme a un régimen superior, pero han experimentado una "cierta progresión" en su tratamiento. De este modo se favorece la flexibilización de sus condiciones de vida y se facilita un mayor contacto con el exterior, a través de su inserción laboral, profesional, social y familiar.

Del examen de los datos sobre la aplicación de este mecanismo de flexibilización, se desprende que se está haciendo un uso frecuente del mismo. Para no tratarse de un régimen con autonomía propia, los datos revelan que se emplea en un porcentaje elevado para modificar el régimen de vida de los clasificados en segundo grado. Así es, en los últimos 9 años se ha aplicado de manera estable, con una ligera tendencia a la baja. Asimismo, los datos de Cataluña muestran que en los últimos tres años (2017-2019) se ha incrementado tanto el número de internos a los que propone la aplicación de este régimen flexible, como el de aquellos que cumplen la pena en régimen abierto. Ello podría significar que la política penitenciaria en esta Comunidad Autónoma ha sido algo más proclive a acordar formas de cumplimiento que implican un mayor grado de libertad, de cumplimiento en la comunidad.

En definitiva, debe concluirse que la validez del régimen flexible dispuesto en el art. 100.2 RP no puede verse comprometida por su aplicación a casos concretos. Su amplio empleo avala su utilidad como instrumento que permite una "transición escalonada hacia la libertad", en particular para aquellos internos que no logran progresar en grado y no pueden cumplir la parte final de la pena en régimen de semilibertad o libertad. Sobre todo, si se tiene en cuenta que en España la mayor parte de los penados finalizan su condena en segundo grado, sin haber obtenido ni el tercer grado ni 
la libertad condicional. Además, entiendo, que de asignarse esta finalidad al régimen estudiado éste podría contribuir a que los condenados que presentan "desventajas" para progresar a tercer grado lograran ver ampliadas sus oportunidades de contacto con el exterior y, quizá, de ese modo reducir la tasa de reincidencia en este colectivo de internos. Más aún sí efectivamente, como parecen haber demostrado un estudio reciente, "el retorno progresivo a la sociedad durante la condenada da mejores resultados para mantener a los internos desistentes del delito" (CAPDEVILA).

\section{Bibliografía}

CAPDEVILA CAPDEVILA, M. (coord.) et al. (2019), "Tasa de reincidencia en la libertad condicional y de inactividad delictiva en 3er grado en Cataluña", $\mathrm{Pu}-$ blicado por el Centre d'Estudis Jurídics i Formació Especialitzada de Catalunya, disponible en: http:// cejfe.gencat.cat/web/.content/home/recerca/cataleg/ crono/2019/taxaReincidencia ES.pdf

CERVELLÓ DONDERÍS, Vicenta, (2005), "La clasificación en tercer grado como instrumento de resocialización", en El juez de vigilancia y el tratamiento penitenciarios, en Estudios de Derecho Judicial, 84.p. 157-204.

CERVELLÓ DONDERÍS, Vicenta, (2016), Derecho penitenciario, $4^{\text {a }}$ Ed. Valencia: Tirant Lo Blanch.

FEIXA EGEA, Gemma, (2012), "Régimen penitenciario/ clasificación y art. 75 del Reglamento Penitenciario. ¿Es el art. 75 RP un nuevo régimen de vida?”, en Revista Electrónica de Ciencia Penal y Criminología n.1409. pp1-24.

FÉREZ-MANGAS, D. y ANDRÉS-PUEYO, A. "Eficacia predictiva en la valoración del riesgo del quebrantamiento de permisos penitenciarios" en LA LEY Penal $\mathrm{n}^{\mathrm{o}} 134$, septiembre-octubre $2018, \mathrm{~N}^{\circ} 134,1$ de sep. de 2018. Pp. 1-14. 
FERNANDEZ ARÉVALO, L y NISTAL BURÓN, J (2012), Manual de derecho penitenciario, $2^{\mathrm{a}} \mathrm{Ed}$, Pamplona: Thomson-Aranzadi.

FERNÁNDEZ BERMEJO, D. (2013), Individualización científica y tratamiento en prisión, en Premio Vitoria Kent, Madrid: Ministerio del Interior-Secretaria Técnica.

FERNÁNDEZ BERMEJO, G. (2014) Individualización científica y tratamiento en prisión.

IBAÑEZ, Aina, (2019), "Progresar hacia el régimen abierto: la visión de los profesionales", en Revista Española de Investigación Criminológica, Artículo 7, número 17. https://doi.org/10.46381/reic.v17i0.155

IBAÑEZ, Aina y CID J. (2016), "La reinserción de las personas que finalizan condena en régimen ordinario", Publicado por el Centre d'Estudis Jurídics i Formació Especialitzada de Catalunya, disponible en: https:// ddd.uab.cat/pub/worpap/2016/164855/ESP reinsercion condena regimen ordinario.pdf

JUANATEY DORADO, Carmen, (2013), Manual de derecho penitenciario, $2^{\mathrm{a}} \mathrm{Ed}$, Madrid: Iustel.

JUANATEY DORADO, Carmen, (2017), "Función y fines de la pena: la ejecución de penas privativas de libertad en el caso de los delincuentes de cuello blanco", en Revista Penal, $\mathrm{n}^{\circ}$ 40- Julio 2017.

LEGANES GÓMEZ, S. (2005), La evolución de la clasifcación penitenciaria, Premio Nacional Vitoria Kent 2004, Madrid: Ed. Ministerio del Interior. Secretaría General Técnica.

MIR PUIG, C. (2015), Derecho penitenciario. El cumplimiento de la pena privativa de libertad, $3^{\mathrm{a}} \mathrm{Ed}$. Barcelona: Atelier.

NISTAL BURÓN, J. (2016), El sistema penitenciario español "de un vistazo", $1^{\circ}$ ed. Barcelona: Arial.

NISTAL BURÓN, J. (2020), "El principio de flexibilidad del artículo 100.2 del Reglamento Penitenciario, Algunas 
cuestiones competenciales. A propósito del Auto del Tribunal Supremo de 22 de julio de 2020. Causa especial 20907/2017", en Revista Aranzadi Doctrinal n.11, diciembre de 2020.

PEDROSA, A. (2019). “A quién dejamos atrás? Explorando los obstáculos de la progresión penitenciaria" en Revista Española de Investigación Criminológica. Artículo 7, Número 17 Disponible en: https://dialnet.unirioja.es/servlet/articulo?codigo $=6877871$. https://doi. org/10.46381/reic.v17i0.471

RODRÍGUEZ ALONSO, A. (2003), Lecciones de derecho penitenciario, $3^{\mathrm{a}}$ ed. Granada: Comares.

TAMARIT SUMALLA, JM, GARCÍA ALBERO, R., RODRÍGUEZ PUERTA, MJ Y SAPENA GRAU, F (2005), Curso de derecho penitenciario", $2^{\mathrm{a}} \mathrm{Ed}$, Valencia: Tirant Lo Blanch.

TAMARIT SUMALLA, JM. (2026), "El sistema penitenciario catalán: fundamento y ejercicio de la competencia", en Revista d'Estudis Autonómics i federal, Presidencia Generalitat de Catalunya, accesible en: https:// presidencia.gencat.cat/web/.content/ambits actuacio/desenvolupament autogovern/iea/publicacions/ REAF-JSG/REAF_articles/REAF-23-abril-2016/ reaf23 tamarit esp.pdf 